\title{
Inefficient lobbying, populism and oligarchy
}

\section{Citation}

Campante, Filipe R., and Francisco H.G. Ferreira. 2007. “Inefficient Lobbying, Populism and Oligarchy." Journal of Public Economics 91 (5-6) (June): 993-1021. doi:10.1016/ j.jpubeco.2006.12.006.

\section{Published Version}

doi:10.1016/j.jpubeco.2006.12.006

\section{Permanent link}

http://nrs.harvard.edu/urn-3:HUL.InstRepos:24865281

\section{Terms of Use}

This article was downloaded from Harvard University's DASH repository, and is made available under the terms and conditions applicable to Other Posted Material, as set forth at http:// nrs.harvard.edu/urn-3:HUL.InstRepos:dash.current.terms-of-use\#LAA

\section{Share Your Story}

The Harvard community has made this article openly available.

Please share how this access benefits you. Submit a story.

Accessibility 


\title{
Inefficient Lobbying, Populism and Oligarchy*
}

\author{
Filipe R. Campante`and Francisco H. G. Ferreira ${ }^{\ddagger}$
}

December 1, 2006

\begin{abstract}
This paper analyses the efficiency consequences of lobbying in a production economy with imperfect commitment. We first show that the Pareto efficiency result found for truthful equilibria of common agency games in static exchange economies no longer holds under these more general conditions. We construct a model of pressure groups where the set of efficient truthful common-agency equilibria has measure zero. Second, we show that under fairly general assumptions, the equilibrium will be biased against the group with the highest productivity of private capital, reflecting the fact that, on the margin, less productive groups find lobbying relatively more rewarding. Finally, as an application, if lobbies representing "the poor" and "the rich" have identical organizational capacities, we show that the equilibrium is biased towards the poor, who have a comparative advantage in politics, rather than in production. If the pressure groups differ in their organizational capacity, both pro-rich (oligarchic) and pro-poor (populist) equilibria may arise, all of which are inefficient with respect to the constrained optimum.
\end{abstract}

${ }^{*}$ We are grateful to Alberto Alesina, Abhijit Banerjee, Francesco Caselli, Quoc-Anh Do, Jan Eeckhout, Elhanan Helpman, Richard Holden, Humberto Moreira, and Andre Sant'Anna for their helpful comments. Many suggestions by the editor, Emmanuel Saez, and two anonymous referees are also gratefully acknowledged. Finally, we thank seminar participants at Harvard University, the University of Pennsylvania, the World Bank, PUC-Rio, the NBER Summer Institute, the V Meeting of the Political Economy Group of LACEA (Cartagena, Colombia), NEUDC 2004 (Montreal), and the ASSA Meetings 2005 (Philadelphia). The usual disclaimer on remaining errors applies. Financial support for the early stages of this research was provided by Faperj.

$\dagger$ Department of Economics, Harvard University. Contact: campante@fas.harvard.edu

¥The World Bank Research Department. Contact: fferreira@worldbank.org 


\section{Introduction}

Lobbies and pressure groups employ productive resources - time and money - in the pursuit of influence over government decisions. There is widespread evidence that such rent-seeking activities have real impact on policy-making. Farm lobbies have successfully sought to maintain high levels of protection for domestic production in a number of places, including the European Union, Japan and the United States. In federal countries, such as the United States, India or Brazil, regional and state representatives often lobby central governments to attract public spending to their states - including spending on education and infrastructure that are subsequently used as "inputs" by private businesses in those areas. In developing countries, it is not uncommon for richer groups to lobby for government spending on high-end infrastructure projects such as airports and universities, while poorer groups lobby for spending on basic sanitation and primary schooling.

Is the influence of lobbies over governments costly, in terms of the aggregate efficiency of resource allocation? And, in addition to any aggregate efficiency losses, do the distortions they promote on government activities benefit some groups at the expense of others? The importance of lobbying as an economic activity has of course long been recognized, as have its potentially deleterious effects on the efficiency of resource allocation. ${ }^{1}$ But the initial view that lobbying was inefficient, which characterized the original literature on rent-seeking, derived from its treatment of the contributions made by lobbies to government agents as deadweight losses. ${ }^{2}$ Once the government is explicitly recognized as an agent in its own right, with its own preferences and resources, the economic analysis of pressure group politics changes.

A dominant theoretical approach to lobbies when payments to the government are not dismissed as deadweight losses is that of common agency, in which lobbying is modeled as a "menu auction". 3 If principals behave truthfully - in the sense of revealing their true preferences, and hence paying as contributions to the agent the maximum amount that they are wiling to exchange for the agent's decision - then it has been shown (by Bernheim and Whinston, 1986, and with greater generality by Dixit, Grossman and Helpman, 1997, henceforth cited as DGH) that the equilibrium of the common agency game is Pareto efficient. This result has been very influential in the political economy literature, having been applied, inter alia, to tax rate policy (DGH,1997, and Dixit,1996)

\footnotetext{
${ }^{1}$ A seminal early treatment can be found in Krueger (1974).

${ }^{2}$ See, for instance, Rodríguez (2004), which follows this rent-seeking literature.

${ }^{3} \mathrm{~A}$ common agency problem is one in which several principals, with different and possibly conflicting interests, try to influence the decisions of a single agent. Unlike most principal-agent setups, common agency games present a non-trivial efficiency issue even under perfect information, as they raise the question of whether an efficient allocation of resources can be achieved when the several principals act in a noncooperative way.
} 
and to the determination of trade tariffs (by Grossman and Helpman,1994, 1995a, and 1995b).

Against this background, this paper makes three points. First, we show that the result that truthful equilibria in common agency games are Pareto efficient hinges on the existence of perfect commitment mechanisms between principals and the agent. While this requirement appears both natural and inconsequential in a static exchange economy setup, it turns out to matter a great deal if time and production are introduced. When the DGH framework is extended to incorporate production and imperfect commitment (due, say, to contract enforcement problems or credit market failures), the truthful equilibrium of the game is almost surely Pareto inefficient, because principals cannot commit to use the output from production to make contributions to the agent.

Second, we make a general prediction about the nature of the inefficiency that arises from lobbying without commitment. We consider a simple model in which two groups have access to different technologies, each combining private capital with a different publicly provided input. These groups therefore have conflicting interests over the composition of public spending, and they make political contributions seeking to influence it. In the absence of enforceable contracts, the equilibrium allocation is shown to be inefficient, because it is excessively tilted towards the group which has the lowest marginal productivity of private capital in equilibrium.

The intuition for this general result is that the group which is relatively inefficient in using private resources (wealth) for production, allocates a greater share of these resources to lobbying, thus distorting public decisions in its favor. This would not occur if future gains from production were also available for lobbying. But, in the absence of commitment, the full surplus from production cannot be used, and the production vs political contribution decision is effectively a portfolio investment decision. Those with a "comparative advantage" in production lobby relatively less, and the equilibrium is distorted in favor of the other group, which may be said to have a "comparative advantage" in politics, rather than production. ${ }^{4}$

Third, we consider the distributional implications of these results in a specific variant of the model, in which access to the more productive technology is endogenized by requiring a minimum level of wealth. This causes the two pressure groups to have different wealth levels, with one poorer than the other. Since the richer group gains access to a more productive technology - by virtue of having greater wealth - the equilibrium of the basic model is inefficiently pro-poor, in the sense

\footnotetext{
${ }^{4}$ This resembles the result from the classic model of competition among pressure groups by Becker (1983), in which the equilibrium depends on relative political productivity between groups. That model, however, does not include production explicitly, so it does not address the issue of political productivity relative to efficiency in production per se. Our results also contrast with those in the model by Acemoglu, Aghion and Zilibotti (2006), in which lobbying under credit constraints always benefits those who have more resources.
} 
that the equilibrium allocation of public spending is excessively tilted towards the poorest lobby (relative to the efficient allocation). Since this is the result of a relatively larger lobbying effort on the part of the poor, we call this a "populist" equilibrium.

Allowing for different levels of organizational capacity within each lobby - so as to capture a possible Olsonian effect of group size (Olson, 1965) - generates a richer gamut of outcomes. In particular, if the richer group is sufficiently smaller and better organized, it is possible to obtain inefficiently pro-rich equilibria, which we call "oligarchic".

Other papers have studied conditions under which the Pareto efficiency property of the equilibria of common-agency games fails. Besley and Coate (2001) obtain inefficiency results within the common-agency framework by abandoning the notion of truthful behavior. ${ }^{5}$ Besharov (2002) generates inefficiency by returning to the notion that contributions are directly wasteful. Of course, the common agency framework is not the only way to model the behavior of interest groups, and a discussion of different approaches can be found in van Winden (2003). Another recent treatment appears in Felli and Merlo (2006), who substitute bargaining for the menu auction formulation.

Our results are also related to those in Loury (1981), Galor and Zeira (1993), and Banerjee and Newman (1993), in the sense that the initial distribution of wealth affects the efficiency properties of the "long-run" equilibrium of the economy. As in those papers, imperfect commitment (which may arise from credit market imperfections) plays a crucial role, although here it does so in a different context, namely a non-electoral political process. In this context, the key inefficiency generated by the absence of commitment arises through a distortion in equilibrium public policy, and is additional to the one stemming simply from the existence of individuals restricted to a less productive technology due to lack of access to credit.

In common with the literature on wealth distribution and political economy (Bertola, 1993; Alesina and Rodrik, 1994; Persson and Tabellini, 1994; Bénabou, 2000), we find that wealth inequality can lead to inefficient equilibria, due to the existence of conflicting preferences over public policy. In contrast with most of it, however, in our model inefficiency does not arise from distortions inherent to the nature of redistribution (such as a tax on capital holdings). Instead, it arises from the very nature of the political process. Whereas those authors emphasize the inefficiencies caused

\footnotetext{
${ }^{5}$ Besley and Coate, 2001, p. 79 state that "Bernheim and Whinston (1986), Grossman and Helpman (1994), and DGH (1997) have all argued that we should expect equilibria with truthful contribution schedules to be played. At the end of the day, however, they do not offer an account of the decision making process which guarantees convergence to these equilibria" (our abbreviation). We do not find the original three arguments in support of truthful behavior as unpersuasive as Besley and Coate do: (i) the efficiency result itself may cause truthful equilibria to be focal; (ii) truthful contribution schedules are always a best response (which implies the existence of truthful equilibria), and (iii) they are the only coalition-proof equilibria.
} 
by tax choices arising from electoral outcomes, we consider inefficient spending decisions, as a result of lobbying from interested pressure groups. ${ }^{6}$

Other papers that are related to ours are Esteban and Ray $(2000,2006)$ and Do (2004), which also look at wealth distribution and political competition over government decisions. Esteban and Ray (2006) consider an imperfect information setup, in which agents lobby in order to signal profitability. The signal can be "jammed", however, by the confounding effect of wealth. Governments do not directly benefit from contributions, which are purely wasteful, but their allocation decisions can be distorted by the superior lobbying ability of the wealthy, conditional on productivity. The result is driven powerfully by the assumptions that wealth and productiviy are uncorrelated, and that the cost of lobbying declines with wealth. Although the setup is quite different from our perfect information common agency game, a comparison of our results (particularly in Section 4) with Esteban and Ray's helps shed light on the central issue of how the correlation between wealth and productivity determines the direction of the biases that arise from government decisions under lobbying. We return to this issue in the Conclusions. Do (2004) also analyzes pressure group interaction under credit market imperfections, but it focuses on the endogenous emergence of barriers to entry in regulated industries, rather than on the allocation of government spending. Finally, our paper also relates to the literature studying oligarchies versus populism, of which Bourguignon and Verdier (2000), Acemoglu (2005), and Mejía and Posada (2005) are examples. These papers, however, do not study a political process based on lobbying, which is our main focus.

The paper is organized as follows. Section 2 makes our first point, by showing that truthful equilibria in common agency games played without commitment in a production economy are generally inefficient. Section 3 makes our second point: it presents a basic model of two pressure groups that have access to different technologies using different publicly provided inputs, and shows that the equilibrium is distorted towards the group with lowest marginal productivity of private capital. Section 4 makes our third point: when access to the different technologies depends on wealth, the efficiency properties of the game have distributional consequences. With identical organizational abilities, the equilibrium is inefficiently pro-poor (or "populist"). If the richer lobby is sufficiently "better organized", inefficiently pro-rich (or "oligarchic") equilibria are also possible. Section 5 concludes.

\footnotetext{
${ }^{6}$ The need to move beyond voting processes in order to understand the economic effects of politics was emphasized by Atkinson (1997, p. 316), "[it seems] important to see how far the findings depend on whether the outcome is governed by the preferences of the median voter, or by the ideology or preferences of political parties, or by political pressure from different interest groups (...). There has been relatively little research by economists which has set side by side different possible explanations of income redistribution".
} 


\section{Inefficient Lobbying: Introducing Production and Imper- fect Commitment to the Common Agency Framework}

In this section, we investigate the consequences of relaxing the assumption of perfect commitment for the efficiency result of the common agency game proposed by DGH (1997). Since commitment issues are essentially immaterial in a one-shot exchange economy, we extend the DGH framework to an economy in which there is production, and production takes time.

\subsection{The Basic Setup}

Following DGH, let there be a (finite) set $L$ of principals - pressure groups, for instance - in which every principal $i \in L$ has continuous preferences denoted by $U_{i}\left(a, c_{i}\right)$, where $a$ is the vector chosen by the agent - e.g. the policy-maker. Principals wish to influence this choice, and $c_{i}$ is a scalar that stands for the payment made with that purpose by principal $i$ to the agent. It is assumed that $U_{i}$ is decreasing in $c_{i}$. The agent has continuous preferences $G(a, c)$, where $c$ is the payment vector, and $G$ is assumed to be increasing in each component of $c$. In words, the agent enjoys being paid, while the principals do not like to make contributions. Principal $i$ chooses a payment schedule $C_{i}(a) \in C_{i}$, which maps every possible action $a \in A$ into a contribution to the agent. Sets $C_{i}$ and $A$ represent institutional and feasibility constraints on possible choices, and it is assumed that $C_{i} \in C_{i}$ implies that $C_{i}(a) \geq 0$ for every $a \in A$, and also that if $C_{i} \in C_{i}$ then any $C_{i}^{*}$, such that $C_{i}^{*}(a) \geq 0$ and $C_{i}(a) \geq C_{i}^{*}(a)$ for every $a \in A$, also belongs to $C_{i}$. That simply means that payments must be nonnegative, and that any (nonnegative) payment smaller than some feasible payment must also be feasible. The analysis then focuses on a two-stage game: in the second stage, the agent chooses the optimal action given the payment functions chosen by each principal, which were defined noncooperatively in the first stage, taking account of the agent's eventual response.

Such a game has a multitude of possible equilibria. Following DGH, most of the literature has focused on truthful Nash equilibria, which are Nash equilibria in which all players adopt truthful strategies. A truthful strategy, in this context, is a truthful payment schedule relative to some utility level: each principal offers the agent a contribution schedule $C_{i}(a)$ that transfers to the agent the full compensating variation that arises from the the agent's action, provided that such payment is feasible. ${ }^{7}$ Truthful equilibria are an attractive refinement because truthful strategies are always a best response; the equilibria are focal, and coalition-proof.

The fundamental result of the common agency literature, due to Bernheim and Whinston (1986)

\footnotetext{
${ }^{7}$ For this reason, truthful payment schedules are also known as compensating payment schedules (see Grossman \& Helpman, 2001).
} 
and generalized by Proposition 4 in DGH (1997, p. 761), establishes the Pareto efficiency of truthful Nash equilibria in this game. It is helpful to go through the argument that underlies its proof: ${ }^{8}$ Denote the set of agent actions and principal contributions in the truthful equilibrium by $\left\{a^{0}, C^{0}\right\}$ (with respect to utility levels $u_{i}^{0}$ ). Now suppose there were a policy vector $a^{*}$ and a payment vector $c^{*}$ that Pareto-dominated the truthful equilibrium pair of $\left\{a^{0}, C^{0}\right\}$. As principal $i$ must be at least as well off as in equilibrium, and once payments reduce its utility, it must be the case that $c_{i}^{*} \leq C_{i}^{T}\left(a^{*}, u_{i}^{0}\right)$, for this is by assumption a truthful schedule. Hence the agent cannot strictly prefer $a^{*}$ and $c^{*}$ to the equilibrium values, following a revealed preference logic: once $a^{*}$ and $\left\{C_{i}^{T}\left(a^{*}, u_{i}^{0}\right)\right\}_{i \in L}$ were available, yet he chose $\left\{a^{0}, C^{0}\right\}$, then he must not prefer the former to the latter. Given that $c_{i}^{*} \leq C_{i}^{T}\left(a^{*}, u_{i}^{0}\right)$, it follows that he also does not prefer $a^{*}$ and $c^{*}$ to the former, for his utility is increasing in each principal's payment. It must therefore be true that the strict inequality that is required to characterize Pareto-dominance is valid for some principal $i$ : some of the principals must strictly prefer $a^{*}$ and $c_{i}^{*}$ to the equilibrium values. This would mean, however, that such principal would not be optimizing in equilibrium: he could have offered $c_{i}^{*}$ in exchange for $a^{*}$, and the agent would have accepted, for he would still be receiving the truthful contributions $C_{j}^{T}\left(a^{*}, u_{j}^{0}\right)$ from every other principal $j$ (and $C_{j}^{T}\left(a^{*}, u_{j}^{0}\right) \geq c_{j}^{*}$, as was seen above). This means that $\left\{a^{0}, C^{0}\right\}$ was not an equilibrium, and this contradiction establishes the Pareto efficiency of truthful equilibria.

The intuition for this result is that competition between the principals enables the agent to extract all of the surplus in the game, and it is therefore in her best interest to maximize that surplus via an efficient allocation. It should be clear that this result relies critically on commitment. The principals commit to the contribution schedules, and the agent commits to the vector of actions she chooses. This reliance on full commitment is implicit in DGH, and it seems both natural and innocuous when we think of both actions being taken simultaneously, in which case adherence to the announced actions is ultimately enforced by the credible threat by either party to renege on its part of the deal, in case of deviation by the other party. But this is not the case if, say, the contributions are to be paid after the agent has already implemented his action. In this case there must be an explicit commitment device, otherwise the agent will anticipate that the principals will renege on their contributions, and the equilibrium will unravel. ${ }^{9}$

\footnotetext{
${ }^{8}$ The heuristic argument is provided by DGH (1997). In order to find a formal proof, however, one must refer to Dixit, Grossman and Helpman (1999).

${ }^{9}$ The issue of commitment arises, in a different context, within the dynamic extension of the common agency game explored by Bergemann and Valimaki (2003). They consider the case where there is no commitment across periods in a repeated game, but not within one game.
} 


\subsection{Production}

Imperfect commitment would be particularly important in a production economy. The key feature of a production economy, in the present context, lies in the distinction between the resources available before and after the productive activity is undertaken. Let us therefore extend the common agency game to the case of a production economy: the agent's choice (of $a$ ) affects the principals' production function, $\Psi_{i}$, and individual utilities depend on this function's (scalar) output. The production technology also uses as an input the resources directly invested by each principal, which will be denoted $k_{i}$. Therefore our setup may be summed up as follows: each principal has continuous preferences $U_{i}\left[\Psi_{i}\left(a, k_{i}\right), c_{i}\right]$, which is increasing in $\Psi_{i}$ and decreasing in $c_{i} . \Psi_{i}$ is increasing in $k_{i}$ and satisfies the Inada conditions; the agent has continuous preferences $G[a, c ; \Psi(a, k)]$, where $\Psi$ is the vector of production outputs and $k$ is the vector of $k_{i} \cdot{ }^{10}$

The existence of a productive activity means that time now matters in this common agency game: resource availability after production is not the same as before it takes place. Under imperfect commitment, it is the availability of resources before production that determines the feasibility constraints for individual principals. To capture this point formally, let us rewrite the common agency problem in a generalized framework, as a three-stage game, rather than the two stages in which it is usually modeled. At stage one, principals announce payment schedules $C_{i}(a) \in C_{i}$, just as usual. At the second stage, the agent chooses a policy vector $a \in A$, and the principals decide how much they will pay simultaneously with the implementation of the chosen policy, $c_{i}^{s}$. Finally, at the third stage, production is realized and principals decide how much will be paid at the end of the game, $c_{i}^{d}$. In other words, it is possible to pay part of the contribution immediately, while postponing some of it, at each principal's discretion, therefore potentially deferring effective payments. Production takes place between the second and third stages.

Denote individual $i$ 's wealth by $w_{i}$ and assume, for simplicity, that each principal's utility depends only on own consumption, which takes place in the final period and equals output minus the final period contribution. ${ }^{11}$ Assume also that credit markets are missing entirely from this economy, and that the wealth distribution is bounded above, so that $1<\partial \Psi_{i}\left(\bar{a}_{i}, w_{i}\right) / \partial w_{i}, \forall i$, where $\bar{a}_{i} \equiv \arg \max _{\mathbf{a} \in A} \Psi_{i}\left(a, w_{i}\right)$ implying that all principals find it preferable to invest all of their wealth,

\footnotetext{
${ }^{10}$ Alternatively, and more generally, one could think of $\Psi_{i}$ as representing the profits resulting from a productive activity, and of the agent's decision as affecting those profits in some way. In that case, a could still represent publicly-provided inputs for private production, but it might also include decisions on subsidies or tariff rates, or indeed anything that enhanced the profitability of private production.

${ }^{11}$ Allowing for consumption in earlier periods obviously changes the levels of investments and contributions, but does not qualitatively affect the main results of the paper. This is discussed in more detail in Section 3 .
} 
rather than to save any of it across the two periods. ${ }^{12}$ This effectively means that the production function $\Psi_{i}$ is the only conduit between initial wealth and final consumption. The absence of credit markets means that principals can not have access to resources beyond their initial wealth, before production takes place. Individual output then depends on the action chosen by the agent and on the resources invested by the principal, $k_{i}=w_{i}-c_{i}^{s}$. We also assume that there is no discounting. We can then formally define the strategic form of the generalized common agency game as follows:

Definition 1 The strategic form of the generalized common agency game is $\Gamma \equiv\left\{N,\left(S_{i}\right)_{i \in N},\left(u_{i}\right)_{i \in N}\right\}$ such that

(i) $N=L \cup\{j\}$, (set of players, where $L$ is the set of principals and $j$ refers to the agent)

(ii) $u_{i}=U_{i}\left[\Psi_{i}\left(a, w_{i}-c_{i}^{s}\right)-c_{i}^{d}\right], i \in L, u_{i}=G\left[a, c^{s}+c^{d} ; \Psi\left(a, w-c^{s}\right)\right], i=j$, (payoffs)

(iii) $S_{i}=\widetilde{C}_{i} \times \widetilde{C}_{i} \times \widetilde{C}_{i}^{\prime}, i \in L, S_{i}=\widetilde{A}, i=j$ (where $\widetilde{C}_{i}$ is the space of functions $f: A \rightarrow C_{i}, \widetilde{C}_{i}^{\prime}$ is the space of functions $g: A \times \widetilde{C}_{i} \rightarrow C_{i}$ such that $g\left(a, c_{i}\right)+c_{i} \in C_{i}$, and $\widetilde{A}$ is the space of functions $h: C \rightarrow A)$, (strategy spaces).

Let us first assume that there is perfect commitment by the principals, meaning that each principal can somehow commit to the announced payment schedule in a credible manner. This may be formally stated by imposing $c_{i}^{s}+c_{i}^{d}=C_{i}(a)$ for every possible $a$ chosen by the agent, indicating that the latter is indifferent between being paid in the second or in the third stage. The set of possible contributions in equilibrium is now conditioned by the possibility of paying after production. Indeed, the maximum possible payment by principal $i, \bar{C}_{i}$, is given by his total output when: (i) the agent chooses the action that maximizes the principal's utility, and (ii) all of the resources initially available are invested in production: $\bar{C}_{i}\left(w_{i}\right) \equiv \Psi_{i}\left(\bar{a}_{i}, w_{i}\right)$.

Given that payments can be made after production and that the principal's utility is increasing in $\Psi_{i}$, which is increasing in $k_{i}$, it is optimal for principal $i$ to invest $w_{i}$ on the production function, setting $c_{i}^{s}=0$ in any subgame-perfect Nash equilibrium. This in turn implies that $w_{i}$ may be considered a parameter in the payoff functions, which can thus be written as $U_{i}\left(a, c_{i}\right)$ and $G(a, c)$ : this is precisely how they appear in DGH (1997). It is then possible to directly apply their Proposition 4, and to conclude that truthful equilibria lead to Pareto-efficient allocations in generalized common agency games with perfect commitment by the principals with respect to announced payment schedules. In fact, within a perfect commitment framework, the introduction of a production activity merely changes the set of possible equilibrium contributions, $C_{i}$.

\footnotetext{
${ }^{12}$ While the missing credit market assumption is crucial for the results, the upper bound on the wealth distribution is an innocuous simplification. It simply prevents us from having to account for some agents investing up to the point where $\Psi_{i}^{\prime}(k)=1$, and saving $k_{i}$ thereafter.
} 
Let us now consider the case in which there is no such perfect commitment mechanism. In this case, proceeding by backward induction in $\Gamma$, a subgame-perfect equilibrium necessarily involves $c_{i}^{d}=0$ : once the policy chosen by the agent has been implemented, principals have no incentive whatsoever to make any further payment, for it would decrease their utilities. Any promise of a strictly positive $c_{i}^{d}$ would not be credible, and the agent will take account of that by demanding that payments be made simultaneously to policy implementation. This means that all payments must be made before production, and that affects the amount of resources available for productive investment in equilibrium, since contributions and investments must both come from initial wealth, $w_{i}$. Formally, there is a new level of the maximum possible contribution by principal i, $C_{i}$, given by $\bar{C}_{i} \prime\left(w_{i}\right) \equiv w_{i}$. The utility functions must now be correspondingly written as $U_{i}\left[\Psi_{i}\left(a, w_{i}-c_{i}^{s}\right)\right]$ and $G\left[a, c^{s} ; \Psi\left(a, w-c^{s}\right)\right]$.

Given that production in this economy is more efficient than a storage technology, $C_{i} /$ is a strict subset of $C_{i}$. A careful analysis of the aforementioned heuristic argument behind the proof of Proposition 4 of DGH (1997) shows that this suffices to break the validity of the proposition as a general result: it could be the case that there existed $a^{*}$ and $c^{*}$ such that $C_{i}^{T}\left(a^{*}, u_{i}^{0}\right), c_{i}^{*} \in C_{i}$ and $C_{i}^{T}\left(a^{*}, u_{i}^{0}\right), c_{i}^{*} \notin C_{i}^{\prime}$, for some $i \in L$, so that the revealed preference argument is no longer valid. To put it another way, the absence of perfect commitment reduces the set of payments that are possible in equilibrium: there may be an allocation which Pareto-dominates the constrained equilibrium one and which is feasible in $C_{i}$, but which is not feasible in the restricted set $C_{i}{ }^{\prime}{ }^{13}$

The crucial element in the above argument is the impossibility of having access to produced resources before engaging in the productive activity. In this sense, the existence of perfect credit markets could play the role of perfect commitment, in that it would allow for the anticipation of future resources. Of course, perfect credit markets require perfect commitment between borrowers and lenders, in the sense of perfect enforcement of contracts. This reveals the very nature of the inefficiency under analysis: it is linked to some institutional problem which gives rise to a contract enforcement failure, either within credit markets or between principals and agent. ${ }^{14}$

As elsewhere in the literature (e.g., Grossman and Helpman, 1994a), this discussion of efficiency applies to the allocation of resources among the players taking part in the game. If there are

\footnotetext{
${ }^{13}$ The maintained assumption here is that the relevant set for efficiency analysis is the one which embodies the technological production possibilities of the economy. The implication is that an equilibrium reached subject to the feasibility constraints implicit in the constrained set of possible equilibrium contributions need not be Pareto efficient in that larger set. This efficiency assessment is analogous to stating that a general equilibrium with a missing market is no longer Pareto efficient (as compared to one with complete markets).

${ }^{14}$ It is possible that commitment devices might emerge in a context in which the game is repeated. As with the standard Folk theorem, their existence would require some upper bound on discount rates.
} 
other individuals in the economy who are not part of the common agency game, there can (and, in general, will) be inefficient outcomes for the economy as a whole, where the outsiders end up being "exploited" by the players, to the detriment of efficiency. ${ }^{15}$

In this section, we have shown that truthful equilibria in generalized common agency games without perfect commitment need not be efficient. In the next section, we consider a simple illustration, in which two exogenously formed groups have access to different technologies. Each uses a different publicly provided good as an input into production, and they lobby the government over the composition of public spending between these goods. The results will shed light on the nature of the ensuing inefficiency, in which public spending is distorted towards the least economically productive group.

\section{A Model of Inefficient Lobbying over the Composition of Public Expenditures}

In order to analyze the nature of the inefficiency generated by lobbying in a production economy with imperfect commitment, some additional structure is necessary. In this section we provide a simple common agency model that incorporates both a time-consuming production process and imperfect commitment, by considering two pressure groups that use different publicly provided inputs, which we denote $g$ and $s$, into their own private production processes. The vector of government actions will now be the vector of the quantities of these two publicly provided goods: $a=\{g, s\}$.

Let the economy consist of a continuum of private individuals forming a population of size one, and of a separate agent, called the "government", whose attributes are discussed below. In this section, let each individual in the continuum be endowed with an identical initial wealth level, w. This initial wealth consists of a single good, which we can be used to pay taxes; to invest in production (in the form of capital good $k$ ); or to make contributions to the government agent. The government uses tax revenues to produce two different kinds of publicly-provided capital, $g$ and $s$. As in the previous section, consumption of the final good takes place after production. ${ }^{16}$ The objective function of the government agent, which will be presented below, implies that it is amenable to private contributions, which can influence its allocation decision between $g$ and $s$. It will thus be rational for private agents to make contributions out of their initial wealth, contingent on the government's actions: $C(g, s)$.

\footnotetext{
${ }^{15}$ Felli and Merlo (2006) show that, in a context where lobbying is modelled as bargaining between an elected official and organized groups, not all groups will actively lobby in equilibrium.

${ }^{16}$ Later in this section we show that our main results are robust to allowing consumption of the initial good.
} 
Private production occurs by means of atomistic projects with inelastic and unit labor supply. Each individual has access to only one of two different technologies, which we will denote Technology 1 and Technology 2 , described respectively by the production functions $\psi^{1}\left(k_{1}, g\right)$ and $\psi^{2}\left(k_{2}, s\right)$. These functions are assumed to be differentiable, increasing and concave in both arguments, homogeneous of degree one, and to satisfy the Inada conditions. A proportion $p$ of the population has access to Technology 1, while the remaining $1-p$ has access to Technology 2 . For the moment, we assume that access to technology is determined exogenously. We relax that assumption in the next section. Since each individual lives for a single period and derives utility only from his own final consumption, his objective will be to maximize disposable income, which will be totally consumed. Capital markets are assumed to be non-existent.

A key - but not necessarily the only - distinction between Technologies 1 and 2 is that the former makes use of $g$, whereas the latter utilizes $s$. The government finances the production of $g$ and $s$ through taxation. It is assumed that the government's taxation technology is such that it can only raise funds through a linear wealth tax at the beginning of the period. The government is subject to a balanced budget constraint:

$$
\tau w=p g+(1-p) s
$$

where $\tau$ is the exogenously given tax rate on initial wealth. ${ }^{17}$ This is what gives rise to a conflict of interests between Groups 1 and 2 over the amount of $g$ and $s$ to be produced by the government. Note also that (1) implies that $s$ may be expressed as a function of $g$, so that with a slight abuse of notation we can rewrite $C(g, s)$ as $C(g) .{ }^{18}$

\subsection{The Political Process}

In keeping with standard practice in the common agency literature, we assume that the two groups have exogenously solved the collective action problem and are articulated as pressure groups, each trying to influence the government's choice between the two types of expenditure, by means of political contributions. Each group promises to pay some amount to the government, depending on the policy vector $\{g, s\}$. These contributions actually stand for a plethora of real-life practices, such as money (or time) devoted to campaign contributions, pure bribery, etc., as in Grossman and

\footnotetext{
${ }^{17}$ Note that political contributions do not enter the budget constraint. One should think of them as going to a party fund, or simply being shifted towards private consumption of the government agent.

${ }^{18}$ This is made possible by the assumption of an exogenous tax rate. If the tax rate were endogenous - say, part of the vector $a$ - then the agent's contribution schedule would be a function of two dimensions: both the level and composition of public spending. Results might then be potentially quite different, and this is an interesting question for further research.
} 
Helpman (1994). We also assume that individuals can only influence government behavior through this channel if they are part of an organized pressure group: each individual perceives himself as too small to influence policy decisions on their own (Grossman and Helpman, 1994).

In line with the previous section, we assume imperfect commitment: there is no way by which either group can credibly commit to meeting their announced political contributions after the government has implemented its decision. As we have seen, this implies that contributions must be paid before production, hence resources available for productive investment must be net of such payments. To summarize the time structure of the model, we can represent life in this one-period economy in the timeline depicted in Figure 1.

\section{[FIGURE 1 HERE]}

Following Grossman and Helpman (1994) and DGH (1997), we assume that the government's objective function is a convex combination (with weight $x$ ) of the contributions it receives and of a social welfare function. This positive weight $(1-x)$ on social welfare can either be interpreted as

allowing for some "benevolence" on the part of the government agent, or simply as capturing the fact that actual political processes are not limited to the interaction of pressure groups, and may also include more "democratic" channels, such as elections, which may induce the government to care about the welfare of the people.

These features may be expressed, drawing upon Grossman and Helpman (1994), by modeling a government that maximizes the following objective function:

$G=x\left[p C^{1}(g)+(1-p) C^{2}(g)\right]+(1-x)\left[p \psi^{1}\left((1-\tau) w-C^{1}(g), g\right)+(1-p) \psi^{2}\left((1-\tau) w-C^{2}(g), s\right)\right]$

where $C^{j}(g)$ is the political contribution from an individual member of group $j$ as a function of the composition of government expenditures. We assume this function to be continuously differentiable. $x \in(0,1)$ is the weight attached to contributions vis-à-vis social welfare (considering, for simplicity, a Benthamite welfare function in which every individual has the same weight). The individual's utility - which is identical to its post-production disposable income - is written in (2) taking into account the fact that, in light of the absence capital markets, initial wealth is fully exhausted by taxes, political contributions and private investment.

Assuming perfect information, the problem is therefore written exactly as a generalized common agency game - where pressure groups are the principals and the government is the agent - and its 
solution may be obtained as such.

\subsection{Results}

As with the standard common agency game discussed in DGH (1997), this game comports a multiplicity of subgame perfect Nash equilibria. As anticipated, we follow Bernheim and Whinston (1986), Grossman and Helpman (1994) and DGH in restricting our attention to truthful symmetric Nash equilibria, since truthful contribution schedules are always a best-response strategy and are the only coalition-proof equilibria of these games. ${ }^{19}$ In this subsection we therefore turn to the efficiency properties of truthful Nash equilibria within this model.

\subsubsection{Inefficiency of the truthful political equilibrium}

First let us characterize in Proposition 1 the efficient allocation in this economy, which will serve as a benchmark for comparisons with the political equilibrium allocation:

Proposition 1 For any given $\left\{k_{1}^{*}, k_{2}^{*}\right\}$, a Pareto-efficient allocation $\left\{g^{*}, s^{*}\right\}$ must have

$$
\psi_{2}^{1}\left(k_{1}^{*}, g^{*}\right)=\psi_{2}^{2}\left(k_{2}^{*}, s^{*}\right)
$$

where the subscript indicates the partial derivative with respect to the corresponding argument.

Proof: See Appendix.

Proposition 1 simply states the obvious requirement that the efficient allocation should equate the marginal product of public capital across the two sectors. It follows directly from the firstorder condition of the problem faced by a hypothetical social planner who wished to maximize a Benthamite social welfare function (or, equivalently, total output) in this economy, by choice of public expenditure, subject to the government budget constraint.

On the other hand, a truthful political equilibrium may be characterized as follows:

Proposition 2 A feasible allocation $\left\{k_{1}^{0}, k_{2}^{0}, g^{0}, s^{0}\right\}$ is a truthful (political) equilibrium only if

$$
\frac{\psi_{2}^{1}\left(k_{1}^{0}, g^{0}\right)}{\psi_{1}^{1}\left(k_{1}^{0}, g^{0}\right)}=\frac{\psi_{2}^{2}\left(k_{2}^{0}, s^{0}\right)}{\psi_{1}^{2}\left(k_{2}^{0}, s^{0}\right)}
$$

Proof: See Appendix.

Proposition 2 is obtained by imposing the requirements that the equilibrium allocation be optimal for the government agent, given the principals' contribution schedules; and optimal for each of

\footnotetext{
${ }^{19}$ Since these truthful symmetric Nash equilibria are equilibria of a game that models a political process - of lobbying to influence government decisions - we sometimes refer to them as "political equilibria" in what follows.
} 
the groups (principals), given the government's feasibility and rationality constraints. The intuition behind the resulting equation (4) is that a political equilibrium equates (across groups) the marginal rates of technical substitution between "investments" in production and in political contributions. This is the result of the principals' effectively having to "purchase" the public capital input, through political contributions, which makes the decision on political contributions inextricable from the decision on productive investment.

The interesting question now is to compare (3) and (4), in order to determine the efficiency properties of the truthful political equilibrium. It is easy to see that the political equilibrium will only be efficient when the groups have the same marginal productivity of private capital at the equilibrium allocation. If the only differences between $\psi^{1}$ and $\psi^{2}$ were their use of different public capital inputs, that equality might be attained. But if the two production functions are different also in terms of the marginal productivity of private capital, equality between the marginal rates of technical substitution at any input ratio will not, in general, imply equality between the marginal products. Generally speaking, therefore, the ratio of the marginal products of private capital $\frac{\psi_{1}^{1}\left(k_{1}^{0}, g^{0}\right)}{\psi_{1}^{2}\left(k_{2}^{0}, s^{0}\right)}$ will not be equal to 1 , and hence $\psi_{2}^{1}\left(k_{1}^{0}, g^{0}\right) \neq \psi_{2}^{2}\left(k_{2}^{0}, s^{0}\right)$. As long as the groups differ in their private capital produtivity, the allocation of public capital across types will fail to equalize their marginal products, and the equilibrium will be inefficient.

It should also be stressed that what is meant by an efficient allocation here does allow for the role of the government as a player: resources used as political contributions are not being considered a deadweight loss, as is usual in the literature on rent-seeking. ${ }^{20}$ The inefficiency that arises in our model is due to the fact that lobbying distorts two key decisions: the composition of government expenditures and the private investment decision of the principals. If there were perfect commitment, the extraction of the full productive surplus by the agent would lead him to separate production from politics in equilibrium and what would prevail would be perfectly analogous to the outcome of the common agency game without production. Without commitment, the two cannot be disentangled, and resource allocation is distorted. Moreover, such inefficiency is not a mere consequence of "corrupt" government behavior: perfect commitment allows for an efficient outcome despite the fact that the government still receives contributions and derives utility from them.

\footnotetext{
${ }^{20}$ To use the terminology of Esteban and Ray (2000), our model features "allocational losses". If one were willing to judge all political contributions as socially wasteful, our model would also feature the "conflictual losses" that are typical of rent-seeking models.
} 
This political inefficiency does not depend on the weight that the government attaches to political contributions vis-à-vis social welfare - as long as this weight remains strictly positive ${ }^{21}-$ which $^{2}$ can be seen from the fact that $x$ does not appear in either (3) or (4). This remark reinforces the observation that the inefficiency stems from the mere existence of lobbying, in the absence of perfect commitment or credit markets. In this sense, it does not depend on how "democratic" the political process turns out to be. ${ }^{22}$

\subsubsection{Understanding the inefficiency}

This very simple model illustrates that generalized common agency games without perfect commitment may indeed be Pareto inefficient - a result which was derived more generally in Section $2 .^{23}$ Let us now briefly analyze the nature of this inefficiency.

Since the technologies are assumed to have constant returns to scale, the marginal products will be homogeneous of degree zero, and we can think of the terms in (3) and (4) as functions of the public-private capital ratios. Suppose, without loss of generality, that Group 2 has a larger marginal productivity of private capital than Group 1 at the equilibrium allocation, i.e. $\psi_{1}^{1}\left(k_{1}^{0}, g^{0}\right)<$ $\psi_{1}^{2}\left(k_{2}^{0}, s^{0}\right)$. This implies, from $(4)$ that $\psi_{2}^{1}\left(k_{1}^{0}, g^{0}\right)<\psi_{2}^{2}\left(k_{2}^{0}, s^{0}\right)$. In order to achieve the equality prescribed by the efficient allocation, we must decrease $\frac{g}{k_{1}}$ relatively to $\frac{s}{k_{2}}$, so that the RHS will decrease, and the LHS will increase (keeping in mind the assumption of concavity of the production functions). We can thus conclude that, in the political equilibrium, Group 2 will have relatively less public capital per unit of private capital than what would be efficient. In this sense, the political equilibrium is biased towards Group 1. It allocates "too much" public spending towards public good $g$, which is used by Group 1 - precisely the group with lower private capital productivity. Since the distortion occurs on the margin, the result does not imply that the least productive group receives a greater allocation of public inputs in absolute terms. The most productive group might well receive more in total, but it will receive less than it would have received in an efficient allocation.

This result is driven by the "comparative advantages" of each group. Since Group 2 is assumed to have an "absolute advantage" in production (a larger marginal productivity of private capital),

\footnotetext{
${ }^{21}$ There is a discontinuity at $x=0$, because as soon as the government places no value on contributions, those go to zero: all principals invest their full initial wealth in private capital, and the government agent provides public inputs efficiently, so as to maximize social welfare. If there is any scope for contributions, the principals will be driven to compete with one another, and in a truthful equilibrium they will offer their compensating variation.

${ }^{22}$ Formally, this result stems from the envelope theorem: when the government considers the impact of a change in the composition of expenditures, the effect on the agents' welfare - the "democratic" component - vanishes because of the first-order condition for agents' optimization. This is a consequence of the concept of truthful equilibrium.

${ }^{23}$ It is easy to check that introducing perfect commitment in our model actually leads to an efficient allocation, which is a mere application of the result due to DGH (1997), but can also be verified by an argument identical to the one used in the proof of Proposition 2.
} 
identical political productivities imply that this group also has a comparative advantage in production, while Group 1 has a comparative advantage in politics. Each group will tend to "specialize" (partially, rather than completely, due to decreasing returns to both types of capital) in the activity in which it has a comparative advantage. Group 1 thus specializes in lobbying, shifting the political equilibrium towards them. The Inada conditions satisfied by the production function ensure that each group does value access to public capital, even when $w$ is very low.

This simple model therefore delivers two key results. First, in the absence of commitment, the truthful political equilibrium of a common-agency lobbying game in an economy with production is generally inefficient. Second, this equilibrium will be biased in favor of the group that has a comparative disadvantage in production. So long as these groups are formed by people who use different technologies, which require different input mixes from the government, one should observe those groups that are relatively less efficient in production spending a greater share of their scarce initial resources lobbying the government, and thereby successfully shifting the government's (marginal) actions to their advantage.

Anecdotal evidence of less productive groups being more successful in lobbying for publiclyprovided inputs, relative to comparatively more productive ones, is not hard to come by. One example is provided by the 2005 transportation bill in the US. A lot of press coverage was devoted to the fact that Alaska obtained over $\$ 1$ billion for transportation projects. In comparison, the state of Washington, with a population nearly ten times as large, received about $\$ 500$ million in total. It is not hard to gauge which state would claim the more productive use of the money: Washington's top transportation project, replacing an earthquake-damaged viaduct used by 110,000 vehicles a day, received just over $\$ 200$ million, which was about the same amount earmarked for Alaska to build a bridge (about as long as the Golden Gate Bridge, and taller than the Brooklyn Bridge) linking a town with 8,000 inhabitants to an island inhabited by 50 people. $^{24}$

In addition, a slightly broader interpretation of the results is possible. As discussed in Section 2, within the context of our model one could think of the vector of government actions as comprising not only different publicly produced inputs, but as also encompassing a broader set of public policies, such as sector-specific tariffs, taxes or regulations, which affect the profitability of private production. Such an interpretation would be consistent with the casual observation that traditional (or declining) sectors are often seen to expend greater effort in lobbying the government than do firms in dynamic,

\footnotetext{
${ }^{24}$ This information was obtained from Bloomberg.com, from Sep. 2, 2005, in an article intitled "Alaska's $\$ 223$ Mln 'Bridge to Nowhere' Envied in U.S. Northwest".
} 
modern sectors. Examples from developed countries include the highly successful lobby of European farmers, and the steel and other "rustbelt" industries in the United States. The perception is that, whereas highly profitable software and internet companies in Silicon Valley spend relatively little on government contributions (relative to $\mathrm{R} \& \mathrm{D}$ investment), that ratio is higher for more traditional sectors, including agriculture and "older" manufacturing industries. ${ }^{25}$

Note, however, that there is nothing in the model that constrains the least productive group (Group 1 above) to represent a "traditional" sector. In a number of developing countries, whose governments pursue "active" industrial policies, the situation may be reversed. "Infant industries" that do not have a comparative advantage in production - such as computer manufacturers in the Manaus "special economic zone" of Northern Brazil - quickly learn that their money is more effectively spent in securing continued subsidies and protection, rather than in seeking to compete with efficient producers elsewhere. The bias of the political equilibrium towards less economically productive groups may thus be useful in understanding a broad range of actual policy outcomes.

\subsection{A Note on Consumption}

It is reasonable to ask whether this key result - of a bias towards the least productive group is robust to allowing for consumption in both stages of the game. In this subsection, we allow for the possibility of private agents consuming part of their initial wealth before production takes place, and show that our assumption ruling out this possibility is in fact innocuous. In other words, introducing intertemporal consumption choice leaves the bias of the political equilibrium towards less economically productive groups unaltered. This is true even if agents face subsistence constraints in the first period. The intuition is that the intertemporal decision between present and future consumption is separable from the "portfolio" decision between investment in production and investment in contributions. Differences in intertemporal choices across the two groups therefore do not translate into differences in the equilibrium private-to-public capital ratios in either group.

To see this more formally, let us extend the model to consider the possibility that some of the initial endowment is consumed directly, rather than invested in production and contributions. Then the problems faced by individuals in each of the two pressure groups are given by:

$$
\begin{array}{ll} 
& \max _{c_{b}^{1}, c_{a}^{1}, C^{1}(\cdot)} u\left(c_{b}^{1}\right)+\beta u\left(c_{a}^{1}\right) \\
\text { s. t. } c_{a}^{1}= & \psi^{1}\left(k_{1}, g\right) \\
& k_{1}=(1-\tau) w-C^{1}(g)-c_{b}^{1}
\end{array}
$$

\footnotetext{
${ }^{25}$ We are grateful to an anonymous referee for making this point.
} 


$$
\begin{aligned}
\max _{c_{b}^{2}, c_{a}^{2}, C^{2}(\cdot)} u\left(c_{b}^{2}\right)+\beta u\left(c_{a}^{2}\right) \\
\text { s. t. } c_{a}^{2}=\psi^{2}\left(k_{2}, s\right) \\
k_{2}=(1-\tau) w-C^{2}(g)-c_{b}^{2}
\end{aligned}
$$

where $c_{b}^{i}, c_{a}^{i}$ denote the consumption level of an individual in Group $i$ before and after production, respectively, and $\beta$ represents a discount rate. We can establish the following:

Proposition 3 If the problem of an individual in Group 1 is described by (5), and the problem of an individual in Group 2 is described by (6), a truthful (political) equilibrium is still characterized by (4).

Proof: See Appendix.

The formal intuition for this result is as follows: this extension of the problem adds two new endogenous variables to be determined, $c_{b}^{1}$ and $c_{b}^{2}$ (since $c_{a}^{1}$ and $c_{a}^{2}$ are residually determined). But it also simply adds two new equations, the Euler equations governing optimal intertemporal allocation, that pin down these new variables. The equations determining the portfolio decision between the two types of investment, in production and contributions, and the optimal allocation of publicly provided inputs, remain unaltered. It follows that the result in Proposition 2, which depended entirely on those three equations, has to hold now as well: The political equilibrium is left unchanged. ${ }^{26}$ We thus conclude that the simplifying assumption of final period consumption is in fact innocuous to the main result, as claimed.

\section{A Lobby of the Rich and a Lobby of the Poor}

The general result presented in the last section has bearing on issues as diverse as protection for agriculture in developed countries, or regional inequalities in government spending in large federal nations, but it may also shed some light on the relationship between lobbying and inequality. If access to technology differs along the wealth distribution, our results on the bias of the equilibrium towards the less economically productive group might also have implications for equity. This is the focus of this section.

We endogenize access to the different technologies by introducing a wealth distribution. Specifically, we now assume that the individuals in the continuum are identical, except for their initial

\footnotetext{
${ }^{26}$ The only assumption needed for this result is the separability of utility before and after production, which is a fairly standard assumption in the context of intertemporal allocation.
} 
wealth, which is distributed as follows: a proportion $p$ of the population has initial wealth $\underline{w}$, while the remaining $1-p$ is endowed with $\bar{w}$, where $0<\underline{w}<\bar{w}$.

In order to make further analytical headway, we adapt the framework from the last section by specifying the following functional forms for each of the two production functions:

$$
\Psi(k, g, s)=\left\{\begin{array}{c}
A(g+\alpha s)^{a} k^{1-a}, k>\widehat{k} \\
B s^{a} k^{1-a}, \text { otherwise }
\end{array}\right.
$$

where $g$ and $s$, just as before, denote the government per capita expenditures on two different kinds

of publicly-provided private goods ${ }^{27}, 0<\alpha<1,0<a<1, A \alpha^{a}>B$. This last assumption means that, given the option, individuals will prefer to use the first technology, which is more productive. Capital markets are still assumed to be non-existent. The presence of the exogenous threshold $\widehat{k}$ represents a nonconvexity of the production set, and gives rise to the possibility of two classes, which will be called "rich" (denoted by the subscript R) and "poor" (denoted by the subscript P). These classes are defined by the initial wealth distribution: assume that $\underline{w}<\widehat{k}$ and $\bar{w}>\widehat{k}+C_{R}\left(g^{0}\right)$ (where $C_{R}\left(g^{0}\right)$ is the equilibrium contribution of a rich individual) and it follows that those individuals with initial wealth $\underline{w}$ are the poor, and those endowed with $\bar{w}$ are the rich. The rich are able to invest at least $\widehat{k}$, and thus have access to a more productive technology, while the poor have to settle for a less efficient one. Since there are no capital markets, investment is limited by initial wealth.

The specification in (7) implies that the publicly-provided goods play a fundamental role in private production (as in Barro, 1990). As before, $g$ and $s$ can be seen as two kinds of "public capital", with differentiated impacts on production: $g$ is useful only to one group (which now consists of "the rich"), while $s$ is more beneficial to the poor (given the assumption on $\alpha$ ). This is meant to capture the fact that there are many types of expenditure which are appropriated exclusively (or predominantly) by the richest strata in society, while other types are more useful to the poor, even though they can also be used by the rich (Ferreira, 1995). Public healthcare or sanitation expenditures may exemplify the latter, while building airports or subsidizing tertiary education in developing countries could illustrate the former. ${ }^{28}$ The important point is that the existence of these

\footnotetext{
${ }^{27}$ The analysis would not be qualitatively changed if we consider public goods instead of publicly-provided private goods (in which case $g$ and $s$ would stand for total government expenditure in each type of good). The analytical expressions that we derive below would be slightly different.

${ }^{28}$ Note that here we allow the rich to partially benefit from $s$, which makes this model slightly different from the one in the previous section. The polar case in which $\alpha=0$, representing expenditures targeted exclusively to the poor, is exactly in line with the model in the previous section. Most of the results that follow will thus be qualitatively unaffected by setting $\alpha=0$. The exceptions, in the comparative statics analysis with respect to changes in inequality, will be noted. In addition to being realistic in the context of rich versus poor, the main role of the assumption that $\alpha>0$ is to simplify the analysis by making one of the two technologies superior to the other, regardless of the government's allocation decision. This facilitates the mapping from wealth differences to differences in access to technology.
} 
two types of expenditures means that the composition of government expenditures has distributional consequences. Equation (1), for the government's budget constraint, is now replaced by:

$$
\tau[(1-p) \bar{w}+p \underline{w}]=(1-p) g+s
$$

While we still assume that the two groups are exogenously articulated as pressure groups, we find it useful - in a context where the rich face the poor in a conflict of interest groups - to allow for differences in organization (or coordination) capacity across the two groups. Still within the tradition of the common agency literature, we stop short of explicitly modeling how each group deals with the collective action problem. Instead, we attach weights to each group's contribution in the government's utility function, representing a given group's relative ease of organization - and thus greater lobbying effectiveness - by a greater weight. The usual argument is that smaller and less disperse groups have a higher probability of actually being formed, due to transaction costs and to the problem of free-riding, and this could be represented by letting these weights depend on each group's size. Within the present context, where the group of the poor (resp. rich) has size $p$ $(1-p)$, we can define these weights as $\lambda_{P}(p)$ and $\lambda_{R}(p)$, where $\lambda_{P}(p)<0$ and $\lambda_{R}(p)>0$, in order to capture this idea. ${ }^{29}$

The government's objective function can thus be rewritten as:

$$
G=x\left[\lambda_{P}(p) p C_{P}(g)+\lambda_{R}(p)(1-p) C_{R}(g)\right]+(1-x)\left[p \Psi_{P}\left(g, C_{P}(g)\right)+(1-p) \Psi_{R}\left(g, C_{R}(g)\right)\right]
$$

where $\Psi_{P}\left(g, C_{P}(g)\right)$ incorporates, via a slight abuse of notation, the fact that the investment in private capital will be $k_{j}=(1-\tau) w_{j}-C_{j}(g)$.

\subsection{Populist and Oligarchic Equilibria}

We can now apply the results from Propositions 1 and 2 in order to state Propositions 4 and 5.

Proposition 4 A Pareto-efficient allocation $\left\{k_{R}^{*}, k_{P}^{*}, g^{*}, s^{*}\right\}$ must have

$$
\frac{k_{R}^{*}}{g^{*}+\alpha s^{*}}=\left[\frac{p}{1-\alpha(1-p)} \frac{B}{A}\right]^{\frac{1}{1-a}} \frac{k_{P}^{*}}{s^{*}}
$$

.Proof: Immediate from application of Proposition 1, to the functional forms in (7).

\footnotetext{
${ }^{29}$ This is an admittedly very reduced-form attempt to allow for differentiated coordination capacities across different coalitions, which may impact on their effectiveness as pressure groups. The classic references are Olson (1965) and Becker (1983).
} 
The functional forms assumed in (7) enable us to express the results in a particularly transparent manner. The expressions $\frac{k_{R}^{*}}{g^{*}+\alpha s^{*}}$ and $\frac{k_{P}^{*}}{s^{*}}$ represent what may be called the private-public capital ratios of the rich and the poor, respectively. In other words: how many units of private capital are invested per unit of public capital obtained by a given individual. Proposition 4 says that those ratios must be related in a precise manner in order to obtain an efficient allocation. The term $\frac{p}{1-\alpha(1-p)}$ is equal to $\frac{p(1-p)}{(1-p)[1-\alpha(1-p)]}$, which is exactly the ratio between the marginal cost to the group of the poor of an increase in the rich-specific type of expenditure $g$ (i.e. a change of the composition of government expenditures) and its marginal benefit to the group of rich. The term $\frac{B}{A}$ reflects the productive efficiency of the poor relative to that of the rich. Therefore an efficient allocation must equate one group's marginal cost to the other's marginal benefit, taking into account their relative efficiency in production.

Proposition 5 (i) A feasible allocation $\left\{k_{R}^{0}, k_{P}^{0}, g^{0}, s^{0}\right\}$ is a truthful (political) equilibrium only if

$$
\frac{k_{R}^{0}}{g^{0}+\alpha s^{0}}=\frac{\lambda_{P}(p)}{\lambda_{R}(p)} \frac{p}{1-\alpha(1-p)} \frac{k_{P}^{0}}{s^{0}}
$$

(ii) Such allocation is almost surely Pareto-inefficient.

Proof: (i) Immediate from application of Proposition 2, plus some straightforward algebraic manipulation. (ii) It is easy to check that $\left[\frac{p}{1-\alpha(1-p)} \frac{B}{A}\right]^{\frac{1}{1-\alpha}}<\frac{p}{1-\alpha(1-p)}$, because of our parametric assumptions of $0<\alpha<1$ and $B<A \alpha^{a}$, which imply $B<A$. Expressions (10) and (11) could therefore be equal only if $\lambda_{R}(p)$ and $\lambda_{P}(p)$ are exactly so as to compensate for that difference. As they are simply parameters, this could only happen by coincidence: the truthful equilibrium allocation will thus be efficient only for a zero-measure set of parameters. Hence, it is almost surely inefficient.

The second part of Proposition 5, where the inefficiency of the political equilibrium is established, relies on the fact that the ratio of private-public capital ratios within each group in (11) will only be equal to that in (10) for specific arbitrary values of the exogenous parameters $\lambda_{P}(p)$ and $\lambda_{R}(p)$. Note that this inefficiency result does not depend on the introduction of the articulation power functions $\lambda_{P}(p)$ and $\lambda_{R}(p)$ in the model. Quite the contrary: it is only by allowing for the possibility that they differ across the two groups that it becomes possible (with probability measure zero in the parameter space) that the political equilibrium attains constrained efficiency. In fact, if both groups have the same articulation power, the truthful equilibrium will always be inefficient, given the differences in productivity between the two groups. This result is simply a variant of the inefficiency result established more generally in Proposition 2, in the last section. 
It is worth emphasizing that the inefficiency under analysis here is not the same one that is usually highlighted in the literature on wealth distribution and capital market imperfections. That inefficiency typically arises because a group of agents is prevented from having access to a more productive technology. In this case, however, what we call an efficient allocation in Proposition 4 already embodies the fact that some agents are constrained to a less productive technology: it is a constrained optimum, or second-best. The equilibrium allocation described in Proposition 5 is therefore inefficient even relative to the constrained optimum. This additional inefficiency is engendered by the political process, through a distortion in the composition of public spending.

The extent of this inefficiency can be measured by the absolute value of $\theta \equiv\left[\frac{p}{1-\alpha(1-p)} \frac{B}{A}\right]^{\frac{1}{1-a}}-$ $\frac{\lambda_{P}(p)}{\lambda_{R}(p)} \frac{p}{1-\alpha(1-p)}$, which is the difference between the private-public capital ratio of the rich (relative to that of the poor) in the efficient allocation and in the political equilibrium. Define the political equilibrium as "pro-poor" (or "populist") if $\theta<0$, and as "pro-rich" (or "oligarchic") if $\theta>0$. These definitions refer to the fact that in the former (resp. latter) case, public spending deviates from the constrained optimum by allocating more (fewer) units of public capital per unit of private capital to the poor than would be efficient. They are presented graphically in Figure 2, where O stands for oligarchic and $\mathrm{P}$ for populist.

\section{[FIGURE 2 HERE]}

It is interesting to note that if $\lambda_{P}(p)=\lambda_{R}(p)$, i.e. if both groups have the same articulation power, then the equilibrium is always populist. To put it another way, if the poor can organize themselves as effectively as the rich, the allocation of public expenditures in the political equilibrium will be more beneficial to them than the efficient allocation. This result may at first appear surprising, as it means that a political system in which the government's decision-making is influenced by private contributions actually turns out to be relatively beneficial to the poor. It is important to note, however, that the poor may well receive less than the rich in absolute terms, in such a populist equilibrium. The pro-poor bias is relative to the efficient allocation, which generally entails spending more (in absolute terms) on the inputs favored by the rich, since they have higher marginal productivities. The same is true of the contribution to investment ratios across the two groups: while $\frac{C_{P}^{0}}{k_{P}^{0}}>\frac{C_{R}^{0}}{k_{R}^{0}}$, the absolute amount of contributions may well be higher for the rich, since they have a large wealth pie to begin with. ${ }^{30}$

\footnotetext{
${ }^{30}$ Because it is defined in relative terms, the "populist equilibrium" result is perfectly consistent with evidence that the rich have greater levels of political participation in many societies (see, e.g., Bénabou, 2000). In addition, there is significant variation in the link between wealth and political participation across countries (Verba, Nie and Kim, 1978). In Latin America, for instance, a much more egalitarian pattern of political participation (in absolute terms)
} 
This is merely an application of the result highlighted in the previous section. Here $\lambda_{P}(p)$ and $\lambda_{R}(p)$ represent each group's "political productivity", i.e. their effectiveness in lobbying the government. Since the rich have an absolute advantage in production (because the most efficient technology requires a minimum level of private capital investment), identical political productivities imply that the rich have a comparative advantage in production, while the poor have a comparative advantage in politics. The poor thus (partially) specialize in lobbying, shifting the political equilibrium towards themselves. In a world where the rich are more productive than the poor (because their greater initial wealth provided them with productive opportunities that were not available to the poor), our model suggests that lobbying will have an inherent populist bias. ${ }^{31}$

While our model is thus consistent with instances in which the "poor" dominate the political process, leading to government policies that are biased against the rich (populism), the introduction of the political productivity parameters also allows for outcomes in which the absolute advantage of the rich in lobbying is so large that the political equilibrium is pro-rich (oligarchic). This requires that $\lambda_{P}(p)<\lambda_{R}(p),{ }^{32}$ which may arise in practice when the rich are a smaller and less dispersed group than the poor.

One might wonder whether the tendency towards "populism" that our model reveals might be offset by the presence of intertemporal choice in consumption. It might be thought, for instance, that with concave instantaneous utility functions - and therefore a higher marginal utility of consumption - the poor would face a higher opportunity cost of pre-production political contributions, relative to the cost faced by the rich. This might offset their comparative advantage in politics, even when they have similar organizational capacities compared to the rich. This is not the case. The same argument presented at the end of the last section applies here: provided that utility is time-separable, the consumption versus investment decision is separable from the decision between productive and political investments. If principals consumed in both stages of the game, the poor would indeed face a higher marginal cost of investing, in terms of forgone utility from consumption. But this effect would be equiproportional for investment in private capital, $k$, and in political contributions, $C(g)$. The comparative advantage result is driven by the "portfolio choice" between $k$ and $C(g)$, which

has been found to hold. Some kinds of political action, such as "communal participation" are in fact "slightly skewed toward the less wealthy". (Gaviria et al., 2004, p.16). The fact that, even though the poor have fewer resources overall, they still display levels of political participation similar to the rich may be suggestive of the comparative advantage bias that gives rise to populist equilibria.

${ }^{31}$ This is in contrast with a different explanation for inefficient lobbying under credit constraints: it could be the case that the political equilibrium is biased towards those who have more resources to pay political contributions, which might not be those with the highest-return projects. This is what happens, for instance, in Acemoglu, Aghion and Zilibotti (2006), where "richer agents can pay greater bribes and [thus] have a greater influence on policy" (p. $37)$.

${ }^{32}$ This is a necessary, but not sufficient, condition. The stronger, sufficient condition is that $\theta>0$. 
remains unaffected, as shown in Subsection 3.3.

\subsection{Comparative Statics: inequality, poverty and efficiency}

Having characterized the inefficiency of the political equilibrium, let us now examine the impact of changes in the wealth distribution on the equilibrium. The distribution of wealth in this economy is fully described by three parameters: one of the wealth levels (say, $\underline{w}$ ); $p$, the proportion of the population which is poor (or equivalently the relative size of the two groups), and $d \equiv \bar{w}-\underline{w}$, which can be thought of as a measure of inequality. In this subsection, we discuss some comparative statics, concerning the effects of changes in $d$ or $p$ on $\theta$, which measures the extent of oligarchic inefficiency of the equilibrium.

Starting with the former, it may seem at first that inequality has no impact on the magnitude of the inefficiency, as $\theta$ is not functionally dependent on $d$. This conclusion, however, depends crucially on the exact nature of the change in $d$, given the nonconvexity of the production set. A decrease in inequality that gives the poor access to the more productive technology, without leading the rich to become poor, takes the economy automatically to the efficient allocation, for any conflict of interests vanishes. All agents would then prefer that the government produce only the $g$ - capital good. If both pressure groups prefer that the government allocates its entire budget to the production of $g$, then the equilibrium of the game is that $C_{i}=0, \forall i$, and $g=\tau[(1-p) \bar{w}+p \underline{w}], s=0$. Contributions (from both lobbies) fall to zero because the government places some inherent value on social welfare (see equation 2). Knowing this, any threat by the government agent to deviate from the above equilibrium is not credible. Principals stick to zero contributions, and the agent maximizes (9) by allocating all tax revenues to the production of $g$.

Conversely, if the transfer between rich and poor makes everyone poor, so that for example $\widehat{k}>\bar{w}>\underline{w}$, then conflict also disappears, with everyone preferring the government to produce $s$. The equilibrium is now given by $C_{i}=0, \forall i, s=\tau[(1-p) \bar{w}+p \underline{w}], g=0$, for analogous reasons. The effect of changes in inequality on inefficiency is discontinuous: a marginal change can have a large impact if it happens to fit one of the above cases. This discontinuity, which arises from the nonconvexity in the production set, is a feature that our model shares with many imperfect-capitalmarket models which also rely on such a nonconvexity (e.g. Galor and Zeira, 1993; Banerjee and Newman, 1993).

On the other hand, a significant change in inequality could have no effect whatsoever, if the resulting wealth distribution still consisted of two groups, each using a different technology, and 
each thus preferring the government to produce a different kind of public good. Our model, like Banerjee and Duflo (2003), is one in which inequality will only lead to inefficiency insofar as it leads to the formation of groups with conflicting interests, because it is the political interaction between the groups that generates a distorted allocation. This link does not stem from any inherently inefficient property of the redistribution activity per se - as it did in Alesina and Rodrik (1994) or Persson and Tabellini (1994). Inefficiency arises from the fact that lobbying power is not necessarily proportional to productive capacity (because principals can not perfectly commit to use their output to pay contributions).

We now turn to the impacts of changes in the relative size of the groups, which is captured by the parameter $p$. To this purpose, we will first state the following:

Lemma 1 The effect of an increase in the proportion of poor people in the economy on $\theta$ can be divided into:

(i) an efficiency-effect, $\frac{1}{1-a}\left[\frac{p}{1-\alpha(1-p)}\right]^{\frac{a}{1-a}}\left(\frac{B}{A}\right)^{\frac{1}{1-a}} \frac{1-\alpha}{[1-\alpha(1-p)]^{2}}>0$;

(ii) and a political effect, with two components:

a) participation-effect, $-\frac{\lambda_{P}(p)}{\lambda_{R}(p)} \frac{1-\alpha}{[1-\alpha(1-p)]^{2}}<0$;

b) coordination-effect, $-\frac{p}{1-\alpha(1-p)}\left[\frac{\lambda_{P}(p)}{\lambda_{R}(p)}-\frac{\lambda_{P}(p)}{\lambda_{R}(p)^{2}} \lambda_{R^{\prime}}(p)\right]>0$.

Proof: See Appendix.

The first effect embodies the impact of an increase in the proportion of the poor on the efficient allocation: as the size of a given group increases, efficiency requires more public capital to be directed toward that group. In that sense, it shifts the efficient "target" allocation in favor of the poor (see Figure 3). A greater $p$ increases $\theta$ because $\theta$ is a signed measure of inefficiency: It measures oligarchic inefficiency. Ceteris paribus, an increase in the share of the poor shifts the target efficient allocation towards the poor, thus increasing the extent of oligarchic inefficiency for any equilibrium. ${ }^{33}$

The second effect refers to the influence of $p$ on the political equilibrium allocation. The participation effect comes from the fact that an increase in a group's size leads, ceteris paribus, to a larger influence on the political process. Thus, as it is defined, it always favors the poor. The effect is negative because, through it, an increase in $p$ reduces the oligarchic nature of the equilibrium. The coordination effect reflects the diminishing ease of coordination that comes with greater size, which tends to reduce the group's political power. Thus, as it is defined, it always favors the rich, and increases the oligarchic nature of the equilibrium.

\footnotetext{
${ }^{33}$ Being the share of the poorest group in this economy, one could think of $\mathrm{p}$ as $\mathrm{P}(0)$, the Foster, Greer and Thorbecke (1984) measure of poverty incidence. It is quite intuitive to think of the relevant "poverty line" in this economy as some threshold between $\underline{w}$ and $\bar{w}$.
} 
What each of these effects will mean in terms of absolute (as opposed to signed) efficiency depends on the nature of the equilibrium from which we are departing: an increase in $\theta$ improves efficiency if the economy is in a populist equilibrium, and reduces it if the economy is in an oligarchic equilibrium. Thus both the efficiency and the coordination effects reduce absolute inefficiency in a populist equilibrium, while increasing it in an oligarchic equilibrium. The participation effect, which is negative, always goes in the opposite direction. This discussion is depicted in Figure 3, for the populist case, and Figure 4, for the oligarchic case: in both cases, efficiency is improved when the two lines are moved towards each other.

\section{[FIGURES 3 \& 4 HERE]}

But the overall effect of $p$ on $\theta$ will also vary because the relative magnitude of the three effects will vary as $p$ varies. In fact, it can be shown that the efficiency effect dominates the participation effect in an oligarchic equilibrium, whereas the reverse obtains in a populist equilibrium. ${ }^{34}$ Since the coordination effect always reinforces the efficiency effect, the overall impact of $p$ on $\theta$ is unambiguous in an oligarchic equilibrium, but ambiguous in a populist equilibrium. ${ }^{35}$ The following proposition formally establishes these results, and summarizes the impacts of an increase in the proportion of the poor on absolute economic efficiency:

Proposition 6 An increase in the proportion of poor people in the economy will:

(i) increase the absolute inefficiency of the political equilibrium, if it is pro-rich;

(ii) have an ambiguous effect on the absolute inefficiency of the political equilibrium, if it is pro-poor: it will increase it only if private capital is productive enough (relatively to public capital) and if the groups' ease of coordination is not too sensitive to their size.

Proof: See Appendix.

The key result from Proposition 6 is that if the political equilibrium is oligarchic, then an increase in the proportion of the poor is guaranteed to lead to greater inefficiency. This outcome is similar to the typical result of the literature relating distribution and efficiency by means of capital-market imperfections (e.g. Galor and Zeira, 1993; Banerjee and Newman, 1993): the greater the proportion of individuals subject to productive constraints due to their initial wealth, the less efficient is the

\footnotetext{
${ }^{34}$ The intuition for this result comes from the fact that the efficiency effect depends on the "economic" productivity of the poor, relative to the rich, while the participation effect depends on their relative productivity in lobbying. An oligarchic equilibrium is precisely a situation where the former is greater than the latter.

${ }^{35}$ In the case where $\alpha=0$, the efficiency effect and the participation effect cancel each other out. In that case, an increase in $p$ will always benefit the rich, by making them relatively better organized. It will thus increase absolute inefficiency whenever the economy is in an oligarchic equilibrium, and decrease it otherwise.
} 
economy. However, here this is closely related to the political process, and that is why it is not a general result in our model. If the economy departs from a populist equilibrium, an increase in the proportion of the poor may lead to greater efficiency ${ }^{36}$, thanks to the coordination effect: if the group's ability to coordinate decreases rapidly with its size, an increase in the proportion of the poor may actually reduce the pro-poor bias of the populist equilibrium.

As a general point, the model allows for a distinction between three different aspects of a political process based on the interaction of pressure groups trying to influence the composition of government expenditures: the productive characteristics of each group, their proportional sizes, and their ease of coordination. The literature on the political economy of redistribution and its links to economic performance usually takes into account only the second of those aspects, the one we call participation effect: the "population" weight of a group within the political system is the essential mechanism linking distribution and efficiency. For instance, we can say that models such as those in Alesina and Rodrik (1994) or Persson and Tabellini (1994) are in some sense similar to our populist equilibria, in which the participation-effect tends to increase inefficiency; while models such as Bénabou (2000) allow for the oligarchic case, in which there is an inefficiently low level of redistribution in equilibrium, and in this case the participation effect runs in the opposite direction. ${ }^{37}$

The two remaining effects, on the other hand, are directly related to our assumptions concerning the political system and the nature of the redistributive variable. The efficiency effect comes precisely from the fact that the composition of government expenditures plays an essential role in production. The coordination effect is obviously linked to the fact that the political process is based on pressure groups. As both of these effects have opposite signs to that of the participation-effect, the model allows for "Olsonian outcomes": an increase in the number of supporters of a populist regime might actually destabilize it, leading to greater efficiency.

\section{Conclusions}

This paper has made three separate but related points. First, it has shown that truthful Nash equilibria in generalized common agency games need not be Pareto-efficient in production economies with imperfect commitment mechanisms. If contracts are not fully enforceable and credit markets

\footnotetext{
${ }^{36}$ Recall that the efficiency concept under consideration is in relation to a constrained optimum, where poor workers have no access to the more productive technology. An increase in poverty might of course increase the efficiency gap between the constrained and unconstraind optima.

${ }^{37}$ The analogy is only valid in very general terms, of course, since those are models of electoral politics, rather than of pressure groups.
} 
are not perfect, resources which might become available to principals after production takes place can not be drawn upon when these principals choose their contribution schedules. This implies that productive decisions cannot be separated from lobbying, which generates inefficiency.

Second, to assess the nature of this inefficiency, we described a specific version of the common agency game where two groups with conflicting preferences over the composition of public spending - driven by their use of different technologies - lobby the government to influence its allocation decision. The equilibria in this game are almost surely inefficient and, more specifically, are always distorted in favor of the group with the lowest marginal product of private capital in equilibrium. This government bias reflects the "comparative advantages" of each pressure group: the economically most productive group (partially) specializes in production (relative to "politics", or lobbying), while the economically least productive group does the opposite. These predictions are consistent with much casual observation of how decisions on public projects often end up benefiting less productive groups, and of how unproductive groups often spend relatively more resources in lobbying. The examples of well-articulated pressure groups representing "traditional" sectors, such as European farmers or the US steel industry, are a case in point.

Finally, the model is applied to a specific context in which access to the superior technology depends on wealth, leading to a game between a lobby of the poor and a lobby of the rich. If the rich group is rich precisely because it is more economically efficient, the equilibrium bias towards the group with a comparative advantage in lobbying leads to what we call a "populist equilibrium": a pro-poor relative bias in government policy. Inefficiently pro-rich (or "oligarchic") equilibria are also possible in this model, if one allows for differential organizational capacities across the two lobbies.

We emphasized the relative nature of this result: "populist" equilibria are characterized by an inefficiently high ratio of "pro-poor" public capital $(s)$ to "pro-rich" public capital $(g)$, and by a higher ratio of political contributions to productive investments among the poor than among the rich. Both of these features are clearly consistent with higher overall contribution amounts by the rich, and higher overall levels of public capital $g$. We also noted that the default "populist" bias of the example in Section 4 was due to the specific way in which access to a superior technology was endogenized. By assuming a minimum wealth pre-requisite for access to the most productive technology, that section focused on a world where wealth and productivity are positively correlated. Under alternative assumptions, such as uncorrelated wealth and productivity, the equilibrium could 
look quite different. ${ }^{38}$ With imperfect capital markets, access to superior technologies does often require some wealth. But one can easily think of other scenarios, such as when an economy is undergoing rapid change, and those who became wealthy with an old technology are now less productive than new start-ups. That scenario, while perfectly consistent with the more general models in Sections 2 and 3, would not be suitable for our assumptions in Section 4.

Overall, our general model of lobbying with imperfect commitment provides an alternative theory of inefficient lobbying, which is consistent with truthful equilibria in common agency games and which generates the intuitive outcome that lobbyists are those who find it most worthwhile to spend their resources in that activity, rather than in production. Their success in shifting government behavior away from the optimal is therefore likely to benefit inefficient sectors. We believe this result can be fruitfully applied to other contexts.

\footnotetext{
${ }^{38}$ See Estebán and Ray (2006) who, in a different informational context, assume wealth and productivity are uncorrelated. By further assuming an exogenous political advantage for the rich (a lobbying cost function that declines with wealth), they generate an outcome where resource misallocation tends to favor the rich. A comparison of the two models is interesting because it illustrates the consequences of, in one sense, polar assumptions: whereas our basic Section 4 assumptions give the rich an advantage in production, theirs give them an advantage in politics.
} 


\section{Appendix}

Proof. Proposition 1

The choice of $g$ that maximizes the economy's output, given $p$ and an amount of private capital for each group, $k_{1}$ and $k_{2}$, is given by solving:

$$
\operatorname{Max}_{g} p \psi^{1}\left(k_{1}, g\right)+(1-p) \psi^{2}\left(k_{2}, s\right) .
$$

Given that $s=\frac{\tau w-p g}{1-p}$, the first-order condition is:

$$
p \psi_{2}^{1}\left(k_{1}^{*}, g^{*}\right)+(1-p) \psi_{2}^{2}\left(k_{2}^{*}, s^{*}\right)\left(\frac{-p}{1-p}\right)=0 \Longrightarrow \psi_{2}^{1}\left(k_{1}^{*}, g^{*}\right)=\psi_{2}^{2}\left(k_{2}^{*}, s^{*}\right) .
$$

The FOC is sufficient because of the concavity of the production functions. Since the Pareto optimality requires that the output be maximized, for there is no disutility of working and only a single period, we have that a Pareto-efficient allocation must satisfy the above equation.

Proof. Proposition 2

Let us first note that in a political equilibrium we have $k_{1}^{0}=(1-\tau) w-C^{1}\left(g^{0}\right)$ and $k_{2}^{0}=$ $(1-\tau) w-C^{2}\left(g^{0}\right)$. We know from Proposition 1 in Dixit, Grossman and Helpman (1997, p. 757) that an equilibrium of the common agency game is characterized by three conditions: (i) feasibility of the contributions, (ii) optimality of the policy vector to the agent within the set of feasible actions, given the principals' payment schedules, and (iii) optimality of policy and payments to every principal, subject to feasibility constraints and to the agent's individual rationality constraint (established by the possibility of ignoring any individual principal). The first condition is satisfied by assumption. If the payment schedule is truthful, the marginal contribution must everywhere exactly equate the marginal benefit derived from a policy change - which must be true, in particular, at the equilibrium. As payment schedules are assumed to be differentiable, condition (iii) requires the following FOCs:

$$
\begin{aligned}
& \frac{d \psi^{1}}{d g}\left(g^{0}\right)=0 \Longrightarrow-\psi_{1}^{1}\left(k_{1}^{0}, g^{0}\right) \frac{d C^{1}}{d g}\left(g^{0}\right)+\psi_{2}^{1}\left(k_{1}^{0}, g^{0}\right)=0 \Longrightarrow \frac{d C^{1}}{d g}\left(g^{0}\right)=\frac{\psi_{2}^{1}\left(k_{1}^{0}, g^{0}\right)}{\psi_{1}^{1}\left(k_{1}^{0}, g^{0}\right)} \\
& \frac{d \psi^{2}}{d g}\left(g^{0}\right)=0 \Longrightarrow-\psi_{1}^{2}\left(k_{2}^{0}, s^{0}\right) \frac{d C^{2}}{d g}\left(g^{0}\right)+\psi_{2}^{2}\left(k_{2}^{0}, s^{0}\right)\left(-\frac{p}{1-p}\right)=0 \Longrightarrow \frac{d C^{2}}{d g}\left(g^{0}\right)=-\frac{p}{1-p} \frac{\psi_{2}^{2}\left(k_{2}^{0}, g_{1}^{0}\right)}{\psi_{1}^{2}\left(k_{2}^{0}, g^{0}\right)}
\end{aligned}
$$

Condition (ii) requires that the government's objective function be maximized. We can simplify the FOC to this problem by noticing that the second term of this function is proportional to the sum of each group's utility, and the derivative of this sum is zero, as seen above. Then we have:

$$
\frac{d G}{d g}\left(g^{0}\right)=0 \Longrightarrow x\left[p \frac{d C^{1}}{d g}\left(g^{0}\right)+(1-p) \frac{d C^{2}}{d g}\left(g^{0}\right)\right]=0 \Longrightarrow p \frac{d C^{1}}{d g}\left(g^{0}\right)=-(1-p) \frac{d C^{2}}{d g}\left(g^{0}\right) .
$$

Using the previous results, we may thus obtain:

$$
p \frac{\psi_{2}^{1}\left(k_{1}^{0}, g^{0}\right)}{\psi_{1}^{1}\left(k_{1}^{0}, g^{0}\right)}=(1-p) \frac{p}{1-p} \frac{\psi_{2}^{2}\left(k_{2}^{0}, g^{0}\right)}{\psi_{1}^{2}\left(k_{2}^{0}, g^{0}\right)} \Longrightarrow \frac{\psi_{2}^{1}\left(k_{1}^{0}, g^{0}\right)}{\psi_{1}^{1}\left(k_{1}^{0}, g^{0}\right)}=\frac{\psi_{2}^{2}\left(k_{2}^{0}, s^{0}\right)}{\psi_{1}^{2}\left(k_{2}^{0}, s^{0}\right)}
$$

The sufficiency of this FOC is assured just as in the proof of Proposition 1. 
Proof. Proposition 3

The solution to this problem must satisfy the same set of conditions described in the proof of Proposition 2. In the present context, this involves five FOCs:

$$
\begin{gathered}
u^{\prime}\left(c_{b}^{1}\right)-\beta u^{\prime}\left(c_{a}^{1}\right) \psi_{1}^{1}\left(k_{1}, g\right)=0 \\
u^{\prime}\left(c_{b}^{2}\right)-\beta u^{\prime}\left(c_{a}^{2}\right) \psi_{1}^{2}\left(k_{2}, s\right)=0 \\
\beta u^{\prime}\left(c_{a}^{1}\right)\left[\psi_{2}^{1}\left(k_{1}, g\right)-\psi_{1}^{1}\left(k_{1}, g\right) \frac{\partial C^{1}}{\partial g}(g)\right]=0 \\
\beta u^{\prime}\left(c_{a}^{2}\right)\left[\psi_{2}^{2}\left(k_{2}, s\right)\left(-\frac{p}{1-p}\right)-\psi_{1}^{2}\left(k_{2}, s\right) \frac{\partial C^{2}}{\partial g}(g)\right]=0 \\
x\left[p \frac{d C^{1}}{d g}(g)+(1-p) \frac{d C^{2}}{d g}(g)\right]=0
\end{gathered}
$$

Equations (12) and (13) are the FOCs with respect to consumption, thus embodying the usual Euler equations governing intertemporal choice. Equations (14), (15), and (16) are the conditions for optimality of contribution decisions for the two groups, and of public good production for the government, respectively. Once one recognizes that the terms in square brackets in (14) and (15) are what needs to be brought to zero, it follows that the last three equations boil down to the three equations that determined the solution in the previous case with no intertemporal choice, as can be seen from the proof of Proposition 2. As a result, the same equilibrium condition applies.

This remains the case even if we impose a subsistence constraint in period 1 , of the form $c_{b}^{i} \geq$ $\bar{c}$.Such a constraint will clearly be immaterial if it is not binding for group i: $c_{b}^{i *} \geq \bar{c}$, where $c_{b}^{i *}$ solves (12) for $i=1$, or (13) for $i=2$.If, however, the constraint is binding for any one group (say, 1), so that $c_{b}^{1 *}<\bar{c}<w(1-\tau)$, then (12) no longer holds. Instead, we have $u^{\prime}(\bar{c})<\beta u^{\prime}\left(c_{a}^{1}\right) \psi_{1}^{1}\left(k_{1}, g\right)$. But the effect of this on (14) is only on the term outside the square brackets, so that (14) still implies

$\psi_{2}^{1}\left(k_{1}, g\right)=\psi_{1}^{1}\left(k_{1}, g\right) \frac{\partial C^{1}}{\partial g}(g)$, as before. Similarly, there are no changes to (16). If the subsistence constraint exhausts full post-tax initial wealth (which is the same for both groups in this Section) $\bar{c} \geq w(1-\tau)$, then there are no investments, contributions, production or second period consumption by either group: $k_{i}=C^{i}(g)=\Psi^{i}=c_{a}^{i}=0, \forall i$.

Proof. Lemma 1

It is enough to take the partial derivative of $\theta$ with respect to $p$. The first term of $\theta$, which corresponds to the parameter associated with the efficient allocation, has a derivative of:

$$
\frac{1}{1-a}\left[\frac{p}{1-\alpha(1-p)}\right]^{\frac{a}{1-a}}\left(\frac{B}{A}\right)^{\frac{1}{1-a}} \frac{1-\alpha}{[1-\alpha(1-p)]^{2}}>0
$$


which is the efficiency-effect. The derivative of the second term, associated with the political equilibrium, may be divided in two components, by the rule of product differentiation: $-\frac{\lambda_{P}(p)}{\lambda_{R}(p)} \frac{1-\alpha}{[1-\alpha(1-p)]^{2}}<$ 0 , which comes from differentiating $\frac{p}{1-\alpha(1-p)}$ (a term that appears in the political equilibrium because of the number of poor and rich contributing to the government and on the social welfare function), and $-\frac{p}{1-\alpha(1-p)}\left[\frac{\lambda_{P} \prime(p)}{\lambda_{R}(p)}-\frac{\lambda_{P}(p)}{\lambda_{R}(p)^{2}} \lambda_{R^{\prime}}(p)\right]>0$, which comes from differentiating $\frac{\lambda_{P}(p)}{\lambda_{R}(p)}$ (a term that represents the political weights associated with each group's ease of coordination). Those are the participation-effect and the coordination-effect, respectively.

Proof. Proposition 6

(i) From Lemma 1 we know that:

$\frac{\partial \theta}{\partial p}=\left[\frac{1}{1-a}\left[\frac{p}{1-\alpha(1-p)}\right]^{\frac{a}{1-a}}\left(\frac{B}{A}\right)^{\frac{1}{1-a}}-\frac{\lambda_{P}(p)}{\lambda_{R}(p)}\right]\left[\frac{1-\alpha}{[1-\alpha(1-p)]^{2}}\right]-\frac{p}{1-\alpha(1-p)}\left[\frac{\lambda_{P}(p)}{\lambda_{R}(p)}-\frac{\lambda_{P}(p)}{\lambda_{R}(p)^{2}} \lambda_{R^{\prime}}(p)\right]$

The second term of this subtraction is negative, given the assumptions on the sign of the derivatives of $\lambda_{R}(p)$ and $\lambda_{P}(p)$. As far as the first term is concerned, we know that the second term in square brackets is positive. In a rich-friendly equilibrium, we have:

$$
\begin{aligned}
\theta & >0 \Longrightarrow\left[\frac{p}{1-\alpha(1-p)}\right]^{\frac{1}{1-a}}\left(\frac{B}{A}\right)^{\frac{1}{1-a}}-\frac{\lambda_{P}(p)}{\lambda_{R}(p)} \frac{p}{1-\alpha(1-p)}>0 \\
& \Longrightarrow \frac{p}{1-\alpha(1-p)}\left[\left(\frac{p}{1-\alpha(1-p)}\right)^{\frac{a}{1-a}}\left(\frac{B}{A}\right)^{\frac{1}{1-a}}-\frac{\lambda_{P}(p)}{\lambda_{R}(p)}\right]>0 \\
& \Longrightarrow\left[\left(\frac{p}{1-\alpha(1-p)}\right)^{\frac{a}{1-a}}\left(\frac{B}{A}\right)^{\frac{1}{1-a}}-\frac{\lambda_{P}(p)}{\lambda_{R}(p)}\right]>0 \Longrightarrow \frac{\partial \theta}{\partial p}>0
\end{aligned}
$$

for $\frac{1}{1-a}>1$. Therefore, if $\theta>0$, an increase in $p$ increases $\theta$, which means greater inefficiency.

(ii) The same reasoning presented above implies that:

$$
\left[\left(\frac{p}{1-\alpha(1-p)}\right)^{\frac{a}{1-a}}\left(\frac{B}{A}\right)^{\frac{1}{1-a}}-\frac{\lambda_{P}(p)}{\lambda_{R}(p)}\right]<0
$$

As $\frac{1}{1-a}>1, \frac{\partial \theta}{\partial p}<0$ (which is equivalent to saying that an increase in $p$ increases inefficiency) requires that $a$ not be too high: private capital must be productive enough, relatively to public capital. Moreover, it also requires the second term in $\frac{\partial \theta}{\partial p}$ to be not too big so as to cause the total effect to be positive. 


\section{References}

ACEMOGLU, Daron. "The Form of Property Rights: Oligarchic vs. Democratic Societies". Cambridge, Mass.: MIT (mimeo), 2005.

ACEMOGLU, Daron, AGHION, Philippe \& ZILIBOTTI, Fabrizio. "Distance to Frontier, Selection, and Economic Growth". Journal of the European Economic Association, v. 4, n. 1, pp. $37-74,2006$.

AGHION, Philippe \& BOLTON, Patrick. "A Theory of Trickle-Down Growth and Development". Review of Economic Studies, v. 64, pp. 151-72, 1997.

ALESINA, Alberto F. \& RODRIK, Dani. "Distributive Politics and Economic Growth". Quarterly Journal of Economics, v. CIX, n. 2, pp. 465-90, 1994.

ATKINSON, Anthony B.. "Bringing Income Distribution in from the Cold". Economic Journal, v. 107, pp. 297-321, 1997.

BANERJEE, Abhijit V. \& DUFLO, Esther. "Inequality and Growth: What Can the Data Say?". Journal of Economic Growth, v. 8, pp. 267-299, 2003.

BANERJEE, Abhijit V. \& NEWMAN, Andrew F.. "Occupational Choice and the Process of Development". Journal of Political Economy, v. 101, n. 2, pp. 274-98, 1993.

BARRO, Robert. "Government Spending in a Simple Model of Economic Growth". Journal of Political Economy, v. 98, n. 1, pp. 103-25, 1990.

BECKER, Gary S. "A Theory of Competition Among Pressure Groups for Political Influence". Quarterly Journal of Economics, v. 98, n. 3, pp. 371-400, 1983.

BÉNABOU, Roland. "Unequal Societies: Income Distribution and the Social Contract". American Economic Review, v. 90, n. 1, pp. 96-129, 2000.

BERGEMANN, Dirk \& VALIMAKI, Juuso. "Dynamic Common Agency". Journal of Economic Theory, v. 111, pp. 23-48, 2003.

BERNHEIM, B. Douglas \& WHINSTON, Michael D.. "Menu Auctions, Resource Allocation, and Economic Influence". Quarterly Journal of Economics, v. CI, n. 1, pp. 1-31, 1986.

BERTOLA, Giuseppe. "Factor Shares and Savings in Endogenous Growth". American Economic Review, v. 83, n. 5, pp. 1184-98, 1993.

BESHAROV, Gregory. "Influence Costs in the Provision of Local Public Goods." Duke University (mimeo), 2002.

BESLEY, Timothy \& COATE, Stephen. "Lobbying and Welfare in a Representative Democracy". Review of Economic Studies, v. 68, pp. 67-82, 2001.

BOURGUIGNON, François \& VERDIER, Thierry. "Oligarchy, Democracy, Inequality and Growth". Journal of Development Economics, v. 62, n. 2, pp. 285-313, 2000.

DIXIT, Avinash K.. "Special-Interest Lobbying and Endogenous Commodity Taxation". Eastern Economic Journal, v. 22, pp. 375-88, Fall 1996.

DIXIT, Avinash K., GROSSMAN, Gene M. \& HELPMAN, Elhanan. "Common Agency and Coordination: General Theory and Application to Government Policy Making". Journal of Political Economy, v. 105, n. 4, pp. 752-69, 1997.

DIXIT, Avinash K., GROSSMAN, Gene M. \& HELPMAN, Elhanan. "Common Agency and Coordination: General Theory and an Application to Tax Policy". Princeton University (mimeo), 1999.

DO, Quy-Toan. "Institutional Trap". World Bank Policy Research WP 3291, 2004. 
ESTEBAN, Joan \& RAY, Debraj. "Wealth Constraints, Lobbying and the Efficiency of Public Allocation". European Economic Review, v. 44, n. 4-6, pp. 694-705, 2000.

ESTEBAN, Joan \& RAY, Debraj. "Inequality, Lobbying and Resource Allocation". American Economic Review (forthcoming), 2006.

FELLI, Leonardo \& MERLO, Antonio. "Endogenous Lobbying." Journal of the European Economic Association, v. 4, pp. 180-215, 2006.

FERREIRA, Francisco H. G.. "Roads to Equality: Wealth Distribution Dynamics with PublicPrivate Capital Complementarity". London: LSE-STICERD (Discussion Paper TE/95/286), 1995.

FERREIRA, Francisco H. G.. "Education for the Masses?: The Interaction between Wealth, Educational and Political Inequalities", Economics of Transition, v. 9, n. 2, pp. 533-552, 2001.

FOSTER, J., GREER, J. \& THORBECKE, E.. "A Class of Decomposable Poverty Measures". Econometrica, v. 52, n. 3, pp. 761-6, 1984.

GALOR, Oded \& ZEIRA, Joseph. "Income Distribution and Macroeconomics". Review of Economic Studies, v. 60, n. 1, pp. 35-52, 1993.

GAVIRIA, Alejandro, PANIZZA, Ugo \& WALLACK, Jessica S.. "Economic, Social and Demographic Determinants of Political Participation in Latin America: Evidence from the 1990's". Latin American Journal of Economic Development, No. 3, p. 151-182, 2004.

GROSSMAN, Gene M. \& HELPMAN, Elhanan. "Protection for Sale". American Economic Review, v. 84, n. 4, pp. 833-50, 1994.

GROSSMAN, Gene M. \& HELPMAN, Elhanan. "The Politics of Free-Trade Agreements". American Economic Review, v. 85, n. 4, 1995a.

GROSSMAN, Gene M. \& HELPMAN, Elhanan. "Trade Wars and Trade Talks". Journal of Political Economy, v. 103, n. 4, pp. 675-708, 1995b.

GROSSMAN, Gene M. \& HELPMAN, Elhanan. Special Interest Politics. Cambridge, Mass.: MIT Press, 2001

KRUEGER, Anne O. "The Political Economy of the Rent-Seeking Society", American Economic Review, v. 64, n. 3, pp.291-303, 1974.

LOURY, Glenn. "Intergenerational Transfers and the Distribution of Earnings", Econometrica, v. 49, pp.843-67, 1981.

MEJÍA, Daniel \& POSADA, Carlos. "Populist Policies in the Transition to Democracy", Brown University (mimeo), 2005.

OLSON, Mancur. The Logic of Collective Action. Cambridge, Mass.: Harvard University Press, 1965.

PERSSON, Torsten \& TABELLINI, Guido. "Is Inequality Harmful for Growth? Theory and Evidence". American Economic Review, v. 84, n. 3, pp. 600-21, 1994.

RODRIGUEZ, Francisco. "Inequality, Redistribution and Rent-Seeking". Economics 83 Politics, v. 16, n. 3, pp. 287-320, 2004.

VAN WINDEN, Frans. "Interest Group Behavior and Influence." in Rowley, Charles \& Schneider, Friedrich (Eds.). The Encyclopedia of Public Choice. Boston: Springer, 2003.

VERBA, Sidney, NIE, Norman H., and KIM, Jae-On. Participation and Political Equality: A Seven-Nation Comparison, Cambridge, UK: Cambridge University Press, 1978. 


\section{Figure 1: The Model's Timeline}

\begin{tabular}{lllll|} 
& & & \\
Individuals & $\begin{array}{l}\text { Groups propose } \\
\text { contribution } \\
\text { start with } w,\end{array}$ & $\begin{array}{l}\text { Government } \\
\text { chooses } g \text { and } s,\end{array}$ & Production \\
pay taxes & $\begin{array}{l}\text { Groups pay } \\
\text { contributions }\end{array}$ & & Consumption \\
& & &
\end{tabular}

Figure 2: Efficient and Equilibrium Allocations in Input Ratio-Space

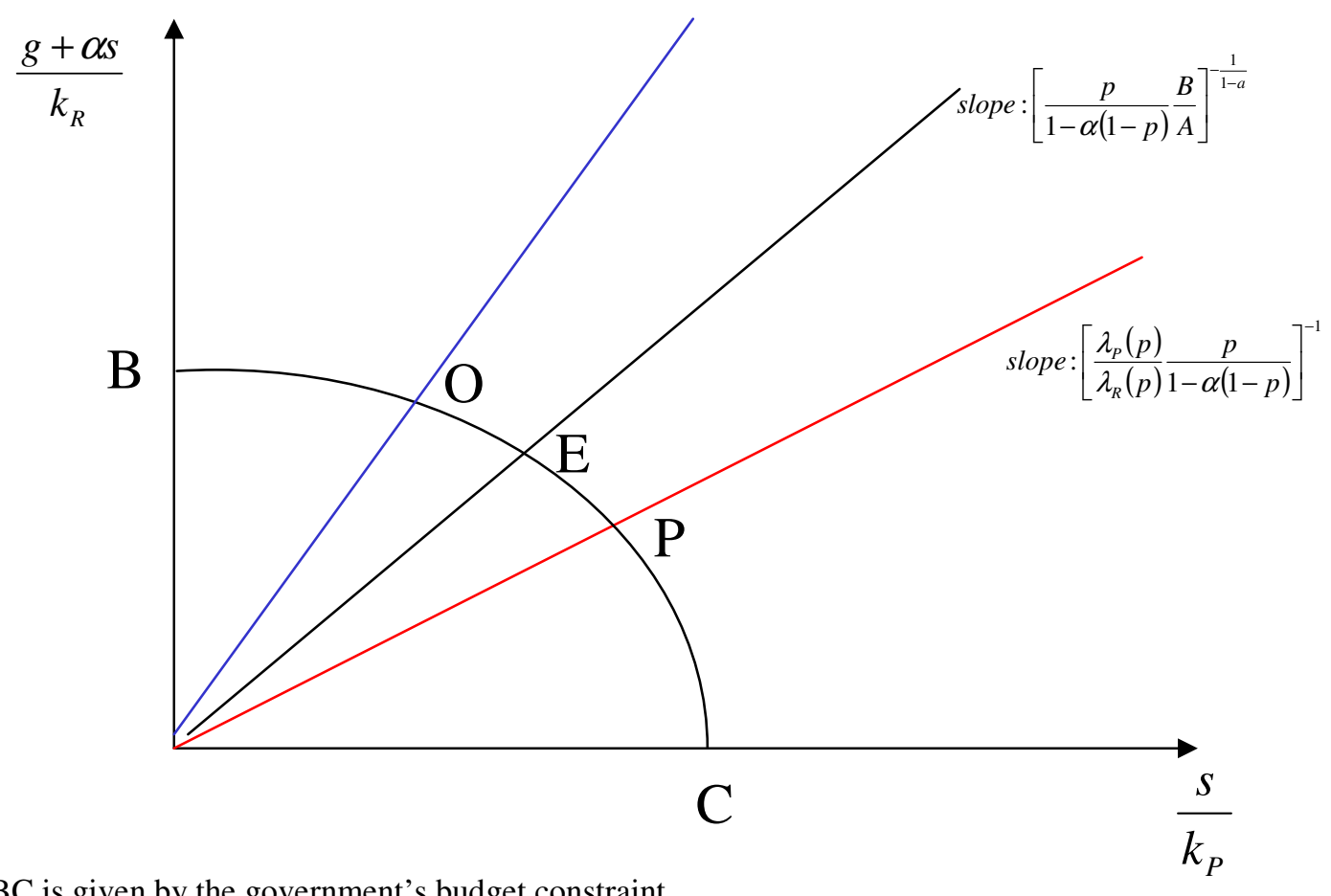

Note: BC is given by the government's budget constraint 
Figure 3: The effect of an Increase in Poverty on a Populist Equilibrium

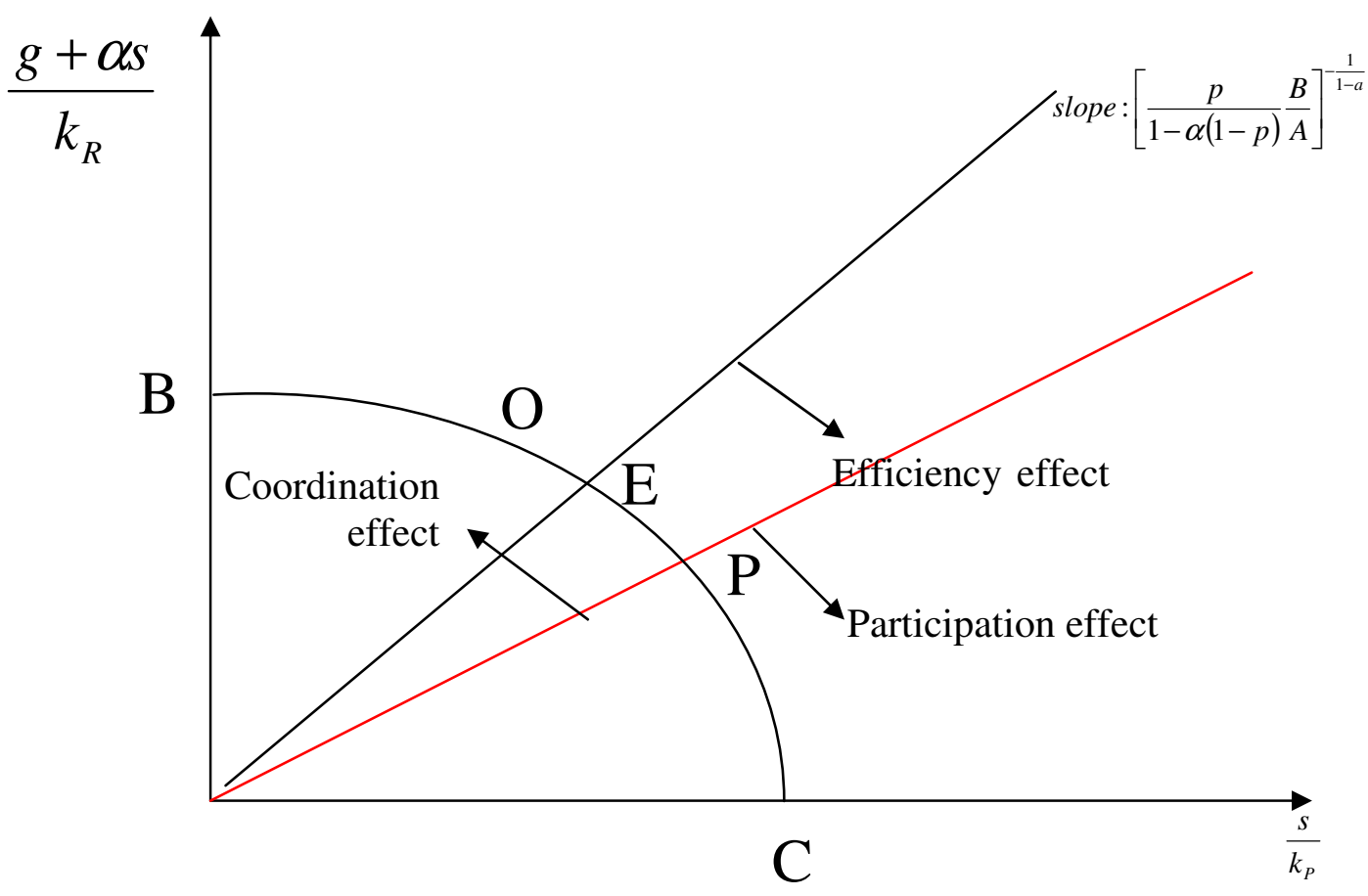

Note: BC is given by the government's budget constraint

Figure 4: The effect of an Increase in Poverty on an Oligarchic Equilibrium

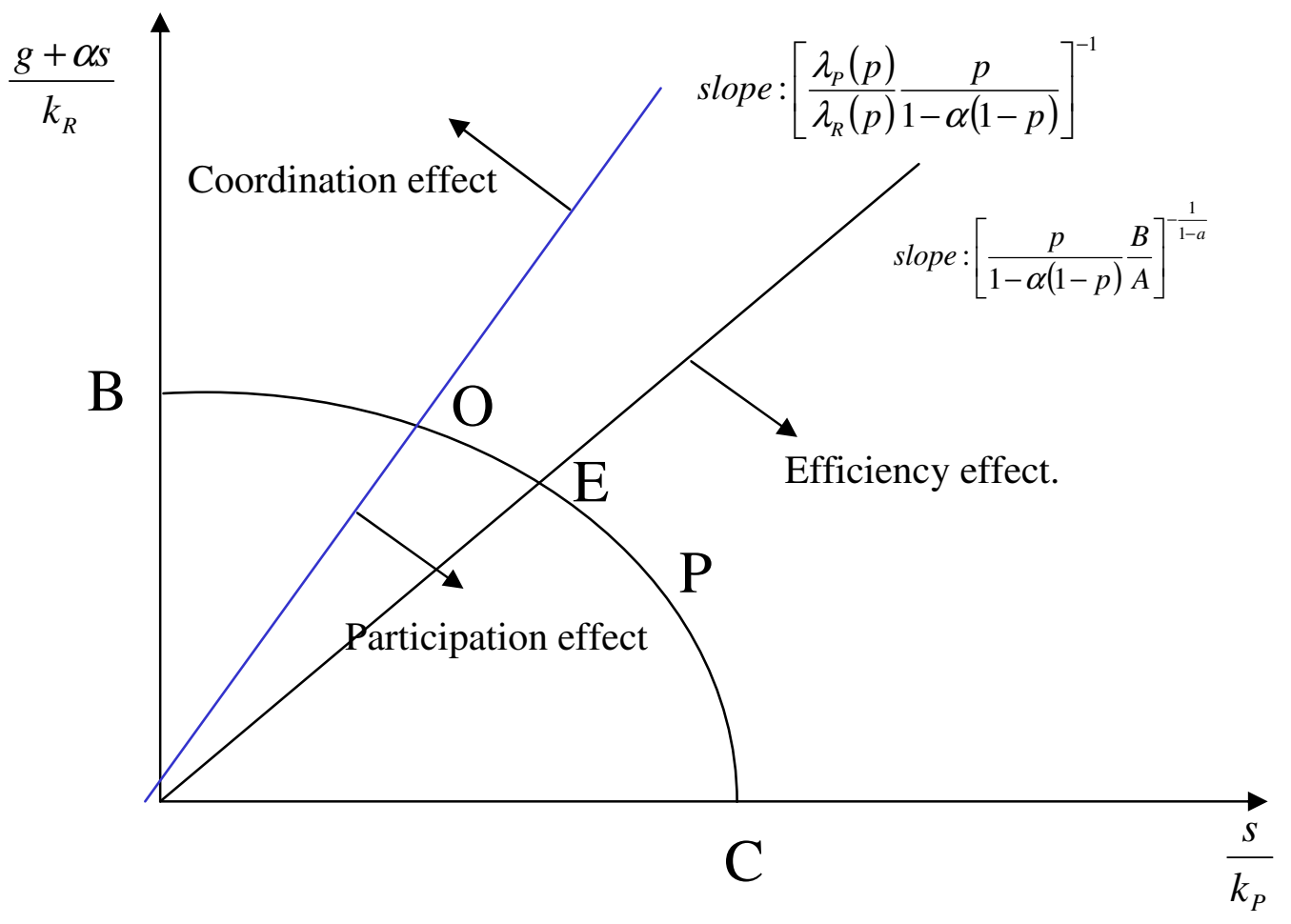

Note: BC is given by the government's budget constraint 